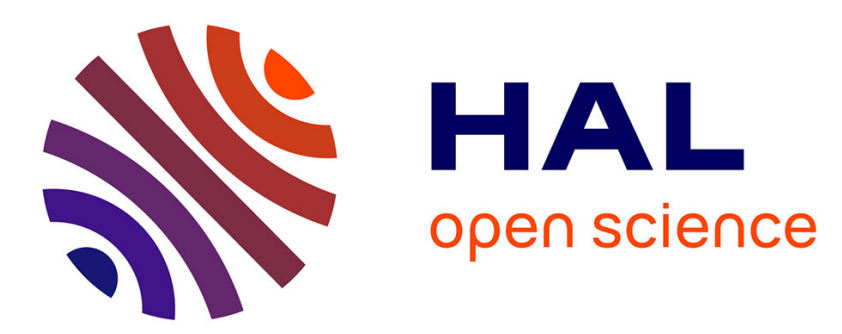

\title{
Analytical solutions for analysing pumping tests near an infinite vertical and anisotropic fault zone based upon unconventional application of well-image theory
}

\author{
Benoît Dewandel, Vivien Hakoun, Sandra Lanini, Claudine Lamotte,
} Jean-Christophe Maréchal

\section{To cite this version:}

Benoît Dewandel, Vivien Hakoun, Sandra Lanini, Claudine Lamotte, Jean-Christophe Maréchal. Analytical solutions for analysing pumping tests near an infinite vertical and anisotropic fault zone based upon unconventional application of well-image theory. Advances in Water Resources, 2022, 160, 10.1016/j.advwatres.2021.104107 . hal-03540594

\author{
HAL Id: hal-03540594 \\ https://hal.science/hal-03540594
}

Submitted on 24 Jan 2022

HAL is a multi-disciplinary open access archive for the deposit and dissemination of scientific research documents, whether they are published or not. The documents may come from teaching and research institutions in France or abroad, or from public or private research centers.
L'archive ouverte pluridisciplinaire HAL, est destinée au dépôt et à la diffusion de documents scientifiques de niveau recherche, publiés ou non, émanant des établissements d'enseignement et de recherche français ou étrangers, des laboratoires publics ou privés. 


\title{
Analytical solutions for analysing pumping tests near an infinite vertical and anisotropic
} fault zone based upon unconventional application of well-image theory

Benoît Dewandel* ${ }^{, 1,2}$, Vivien Hakoun ${ }^{1,2}$, Sandra Lanini ${ }^{1,2}$, Bernard Ladouche ${ }^{1,2}$, Claudine Lamotte $^{1}$ and Jean-Christophe Maréchal ${ }^{1,2}$

(1) BRGM, Univ Montpellier, Montpellier, France

(2) G-eau, UMR 183, INRAE, CIRAD, IRD, AgroParisTech, Supagro, BRGM, Montpellier, France

b.dewandel@brgm.fr; v.hakoun@brgm.fr; s.lanini@brgm.fr, b.ladouche@brgm.fr; c.lamotte@brgm.fr; jc.marechal@brgm.fr

* Corresponding author

\begin{abstract}
We present a new set of analytical solutions for analysing pumping tests in a well near a vertical fault zone, dyke or vein. We consider a fault zone with finite width, storativity and hydraulic conductivity, which can be anisotropic, and without limitation of the diffusivity contrast between the three aquifer domains (pumped aquifer, fault zone and opposite-side aquifer). This configuration, not described before, also considers flow transience within the fault zone. Drawdown solutions were developed for the three-aquifer domains based on an unconventional application of the well-image theory. Their comparison with numerical modelling results was very satisfactory. Drawdown behaviour at the pumping well is discussed for contrasted properties between the three-aquifer domains. Original analytical solutions for transient flow along both sides of the fault zone, and net transient flow from the fault itself, are proposed and discussed, with particular attention to flow reversal, from the pumped compartment to the fault zone, which occurs where the fault zone is the most transmissive. Finally, we extend the solutions to the case of a well intersecting and pumping a vertical fracture of finite length located near the same vertical geological discontinuity.
\end{abstract}

Keywords: Pumping test, Anisotropic fault, Pumping near a fault, Compartmented aquifer, Analytical solution 


\section{Introduction}

In hydrogeology, the oil-and-gas industry, and geothermal activities, well testing is an essential tool for assessing the hydrodynamic properties of a reservoir. The evaluation of these properties, as well as their variability in space, is essential for improving resource management (e.g., Raghavan, 2004; Dewandel et al., 2012). In addition, detailed groundwater flow conditions, particularly in fractured systems, are required for pressure and transfer modelling, for instance in the case of a nuclear-waste deposit, geothermal exploitation, or contaminant transport. Therefore, the design of an adequate conceptual model based on welltest data prior to quantification of the hydrogeologic parameters has been a topic of interest for decades (Bourdet et al., 1983, 1989; Ehlig-Economides, 1988; Renard et al., 2009; Rafini and Larocque, 2012; Ferroud et al., 2019, etc.).

A common case encountered in the field is a well located near a fault (Fig. 1a) that may act as a barrier or a conduit, or a combination of both, to flow (e.g., Maslia and Prowell, 1990, Haneberg, 1995, Bense et al., 2003). In sedimentary rock, but not only, faults may be permeable, or act as low- or non-permeable structures, because the throw along the fault plane may be such that a permeable layer on one side of the fault is completely, or partially, juxtaposed against an impermeable layer on the other side, or because of low hydraulic conductivity materials in the core of the fault zone. The reverse is also possible, where the rock's hydraulic conductivity is enhanced because of unaltered fracturing along the fault zone (Caine et al., 1996). Other geological features, such as dykes, veins, or karst conduits, may locally enhance the hydraulic conductivity, and drain the surrounding aquifer, or act as a barrier or low-permeability discontinuity to flow (Dewandel et al., 2011, Perrin et al. 2011; Lachassagne et al., 2011, 2021, Maréchal et al. 2014; Xiong et al., 2017; Xu et al., 2018).

Depending upon the properties of the fault or of the geological discontinuity, fluid flow may occur along the structure and across the structure's planes. Several analytical studies have described transient pressure behaviour in the pumping well and flow processes; such work often refers to a pumping well near a fault of infinite length with finite-conductivity (Abbaszadeh and Cinco-Ley, 1995, Abbaszadeh et al., 2000; Escobar et al., 2013). Yaxley (1987) derived an analytical solution from Bixel's et al. (1963) work for a well located near a partially communicating vertical fault. This model, dedicated to low-permeable barrier, does not account for flow along the fault plane. Abbaszadeh and Cinco-Ley (1995) presented a 
solution for a well located near a finite-conductivity vertical fault, with fracture skin for simulating damage zones on the sides of the fault plane. Their solution allowed varying aquifer properties on both sides of the fault, considered flow along and across the fault plane, but assumed a small fault width and neglected fault storativity and thus flow transience in the fault zone, the net flux in/out of the fault being nil. This model was dedicated to fault zones with higher hydraulic conductivity than those of the surrounding aquifers. Later, Rahman et al. (2003) proposed a semi-analytical solution similar to Abbaszadeh and Cinco-Ley (1995)'s work, to account for transient flow in the fracture plane, but also assumed a greater hydraulic conductivity in the fault. Other solutions exist in the literature, such as that developed by Boussila et al. (2003) for a well near a linear leaky boundary in laterally infinite composite systems, or the one proposed by Althawad (2016) for a pumping well intersecting and pumping a finite conductivity fracture of infinite length near a finite conductivity fracture of infinite length.

Vertical faults, or other vertical geological discontinuities, can also be conceptualized as vertically compartmented aquifers. Butler and Liu (1991) and Dewandel et al. (2014), proposed solutions for investigating the influence of a pumping well located in a linear strip aquifer — representing the geological discontinuity—bounded laterally by aquifers of differing properties. However, no analytical solution was provided for a pumping well located in one of the two external compartments and thus near the geological discontinuity. Anderson (2006), using the method of images, presented an analytical solution for a pumping well near such a discontinuity. His solution allows considering the anisotropy in hydraulic conductivity of the central compartment, the one representing a vertical fault zone, or another vertical geological discontinuity. However, this solution was established for steady-state flow only. Rafini and Larocque (2009) used numerical models for assessing the flow behaviour induced by a pumping test near a fault zone, embedded in a low-permeable matrix with various fault inclinations, but they did not consider the anisotropy in hydraulic conductivity of the fault zone.

We propose new analytical solutions for drawdown induced by a pumping well near an infinite sub-vertical and anisotropic fault zone (or another vertical geological discontinuity). We consider a fault zone of finite width, storativity and hydraulic conductivity that can be anisotropic (Fig. 1a), without limitation of the diffusivity contrast between the three-aquifer domains (pumped aquifer, fault zone and opposite-side aquifer), which was not considered in earlier works. Our solutions are based upon an unconventional application of the well-image 
theory. Solutions are first developed for an isotropic fault and then extended to the anisotropic case; they are given for the three-aquifer domains and are compared to numerical modelling. The hydrodynamic signatures of drawdown and flow behaviour at the pumping well are discussed. Analytical solutions for transient flow along both sides of the central compartment (the fault zone) are given in terms of spatial and transient evolution, with particular attention to reversed flow, i.e. flow from the pumped compartment entering the fault zone, which can occur under specific conditions. These new solutions allow discussing the transient behaviour of such flow, which has not been studied in the past. Finally, we show that the solutions can be extended to other cases, such as a well intersecting and pumping a vertical fracture of finite length located near an infinite vertical fault zone (Fig. 1b).

The proposed solutions should be useful for examining and modelling drawdown created by a pumping well, or a well intersecting and pumping a vertical fracture, near a vertical fault zone, or another vertical geological discontinuity, such as dykes, veins, buried channels embedded in other materials, or even karst conduits.

\section{Theoretical method and mathematical model}

\subsection{Conceptual model}

The problem of interest consists in evaluating drawdown as a function of coordinates $x, y$ and time, caused by a pumping well near an infinite vertical fault (or geological discontinuity) with finite thickness, finite storativity and anisotropic hydraulic conductivity (Fig. 1a). Following Anderson's (2006) nomenclature, the system is divided in three domains, D1, D* and D2, with L1 representing the boundary between D1 and D*, and L2 the one between $\mathrm{D}^{*}$ and D2. Domain D*, the infinite vertical fault, separates two semi-infinite half-spaces. The pumping well is located in D1; it is at the origin of a Cartesian coordinate system $(x=0, y=0)$ and is at a distance $a$ from L1. The $y$-axis is parallel to the two boundaries L1 and L2. The well fully penetrates the aquifer and produces at a constant flowrate $Q$. The overall domain (D1, D*, D2) assumes a confined condition; each domain is characterized by its own transmissivity and storativity. D* has anisotropic hydraulic conductivity in the horizontal plane, while the two other domains are isotropic. Domain thicknesses can be different (not shown on Fig. 1a). Damage zones along the fault zones $\left(D^{*}\right)$ are not considered. 


\subsection{Method of images}

The method of images is a classic technique for tackling boundary-value problems, such as those encountered in heat conduction, electrostatics, and, particularly, in groundwater flow, to solve the problem of no-flow, constant boundaries, or leaky boundaries (Ferris et al., 1962; Kruseman et al., 1990; Bruggeman, 1999; Anderson, 2000, 2006). Solutions with this method have the advantage of providing convenient forms, compared to solutions from differential equations that may require numerical inversion of a Laplace transform. The proposed solutions are based upon an unconventional application of the well-image theory. This method, originally proposed by Fenske (1984) for the case of a boundary separating two aquifers with dissimilar diffusivities, and later extended by Dewandel et al. (2014) to a well located in an infinite linear strip aquifer limited on both sides by aquifers of differing properties, has been further developed for the case presented here. Though good and useful approximations, the proposed solutions are not shown to be exact solutions to the appropriate partial differential equations (Bixel et al., 1963; Butler and Liu, 1991; Appendix A, hereafter). We do believe, however, that —although it is not the method used here-drawdown solutions can also be obtained by numerical inversion of a Laplace transform.

In a general manner and using the well-image theory for the case presented here, one can consider the drawdown in domain D1 to consist of two components: direct drawdown caused by the pumping well, and reflected drawdowns caused by the reflection of image-well drawdowns from the two boundaries onto D1. Total drawdown can be represented by a sum of drawdowns caused by the pumping well and that caused by image-wells located across the boundaries; each image-well is strengthened to consider the contrast in properties between the three domains. Figure 2a shows the solution for drawdown in D1, where each dot corresponds to an image well with its distance from the pumping well and its strength. This technique is widely used for solving the particular cases of no-flow and constant-head boundary conditions (e.g. Ferris et al., 1962; Kruseman et al., 1990); in these cases, image strength is 1 or -1 . More information on the well-image theory can be found in Anderson $(2000,2006)$, or in Bruggeman (1999).

The drawdown in domains $\mathrm{D}^{*}$ and D2 is the transmitted drawdown across the boundaries. Its solutions depend upon the properties of the domain of interest and are analogues of the solution in D1. Consequently, drawdown can also be represented as the sum of drawdowns caused by the producing well, and one or two infinite well-image series-depending upon the 
domain - lying outside the domain of interest, whereby each pumping- and image well was strengthened to cover the aquifer properties of each domain (Figs. 2b and 2c).

Along the boundaries, conditions vary from boundary L1 (between D1 and D*) to boundary L2 (between D* and D2) and the following criteria must be satisfied:

1). Drawdown must be equal on both sides of the boundaries:

- then $s_{1}(a, y, t)=s^{*}(a, y, t)$ along boundary L1, - and $s_{2}(a+h, y, t)=s^{*}(a+h, y, t)$ along boundary L2,

2). Unit discharge orthogonal to the boundaries must be equal on both sides as well:

$$
\begin{aligned}
& \text { - then } T_{1} \frac{\partial s_{1}(a, y, t)}{\partial x}=T^{*} \frac{\partial s^{*}(a, y, t)}{\partial x} \text { along boundary L1, } \\
& \text { - and } T_{2} \frac{\partial s_{2}(a+h, y, t)}{\partial x}=T^{*} \frac{\partial s^{*}(a+h, y, t)}{\partial x} \text { along boundary L2, }
\end{aligned}
$$

where $s_{1}(x, y, t), s^{*}(x, y, t)$ and $s_{2}(x, y, t)$ are the drawdowns in each domain (D1, D* and D2), $T_{1}$, $T^{*}$ and $T_{2}$ are the transmissivity values of each domain, $a$ is the distance from the pumping well to boundary L1, and $h$ is the width of domain $\mathrm{D}^{*}$.

\subsection{General solutions for drawdown}

Here, we first considered the case where domain $\mathrm{D}^{*}$ is isotropic. A second section deals with the anisotropy of this domain. All three domains are characterized by dissimilar diffusivity values $\left(T_{1} / S_{1} \neq T^{*} / S^{*} \neq T_{2} / S_{2}\right)$.

Using the well-image theory described above, the general solutions for drawdown valid for each domain are expressed as series (Fig. 2). For domain 1 (D1), drawdown is expressed by that of the producing well, that of one image-well at the opposite of L1 (at $x=2 a$ ), and that of one infinite image-well series lying outside D1. For domain D*, drawdown is expressed by two infinite image-well series lying outside D*, and for D2 by one infinite image-well series lying outside D2.

The general form of solutions for drawdown are as follows, for an observation well in domain D1: 


$$
\begin{gathered}
s_{1}(x, y, t)=\frac{Q}{4 \pi T_{1}}\left\{\mathrm{~W}\left(\frac{S_{1}}{4 T_{1} t}\left(x^{2}+y^{2}\right)\right)+\alpha_{0} \mathrm{~W}\left(\frac{S_{1}}{4 T_{1} t}\left([2 a-x]^{2}+y^{2}\right)\right)\right. \\
\left.+\sum_{n=2,4,6}^{\infty} \alpha_{i} \mathrm{~W}\left(\frac{S_{1}}{4 T_{1} t}\left([2 a+n h-x]^{2}+y^{2}\right)\right)\right\}
\end{gathered}
$$

For domain $\mathrm{D}^{*}$ :

$$
\begin{aligned}
s^{*}(x, y, t)= & \frac{Q}{4 \pi T^{*}}\left\{\sum_{n=2,4,6}^{\infty} \beta_{i}^{\prime} \mathrm{W}\left(\frac{s^{*}}{4 T^{*} t}\left([2 a+n h-x]^{2}+y^{2}\right)\right)\right. \\
& \left.+\sum_{n=0,2,4}^{\infty} \beta_{i} \mathrm{~W}\left(\frac{s^{*}}{4 T^{*} t}\left([2 n h+x]^{2}+y^{2}\right)\right)\right\}
\end{aligned}
$$

And for domain D2:

$$
s_{2}(x, y, t)=\frac{Q}{4 \pi T_{2}}\left\{\sum_{n=0,2,4}^{\infty} \delta_{i} \mathrm{~W}\left(\frac{S_{2}}{4 T_{2} t}\left([2 n h+x]^{2}+y^{2}\right)\right)\right\}
$$

where $\mathrm{W}(u)$ is the well-function (or exponential integral function also noted -Ei $[-u]$ ); $S_{l}$ and $T_{1}\left(\mathrm{~m}^{2} / \mathrm{s}\right)$ are the storage coefficient and transmissivity of the aquifer in D1, respectively; $S^{*}$ and $T^{*}\left(\mathrm{~m}^{2} / \mathrm{s}\right)$ are those of the strip aquifer in $\mathrm{D}^{*}$, and $S_{2}$ and $T_{2}\left(\mathrm{~m}^{2} / \mathrm{s}\right)$ those of aquifer D2; $a(\mathrm{~m})$ is the distance from the pumping well to $\mathrm{L} 1$; and $Q$ is the pumping rate $\left(\mathrm{m}^{3} \mathrm{~s}^{-1}\right) ; \alpha_{0}, \alpha_{n}$, $\beta_{i}{ }^{\prime}, \beta_{i}$ and $\delta_{i}$ are the image-well strengths. Now, we must evaluate the strength coefficients of each image-well.

\subsection{Drawdown solutions for the three domains}

\subsubsection{Isotropic case}

200 We consider the first series of images according to L1 and L2 (Fig. 3a). The pumping well is 
L1 $\left(s_{1}(a, y, t)=s^{*}(a, y, t)\right.$ and $\left.T_{1} \frac{\partial s_{1}(a, y, t)}{\partial x}=T^{*} \frac{\partial s^{*}(a, y, t)}{\partial x}\right)$ is that the two strength coefficients $\alpha_{0}$ and $\beta_{0}$ depend upon the contrast of diffusivity between domains D1 and $\mathrm{D}^{*}$, the distance to the boundary $(a)$ and time $(t)$. Appendix B gives the detail of their solutions. This case refers to the influence of a partial hydrologic barrier that separates two domains with contrasted diffusivities, where the drawdown solutions for both domains D1 and D* correspond to the ones proposed by Fenske (1984). Then, considering the case of two parallel boundaries L1 and L2, and thus that of a well pumping near an infinite strip aquifer, the pumping well must be imaged about the second boundary L2 ( $2^{\text {nd }}$ image), which allows evaluating strength coefficients $\beta_{0}$ ' and $\delta_{0}$ (Fig. 3a), while applying the new boundary conditions $\left(s_{2}(a+h, y, t)=\right.$ $s^{*}(a+h, y, t)$ and $\left.T_{2} \frac{\partial s_{2}(a+h, y, t)}{\partial x}=T^{*} \frac{\partial s^{*}(a+h, y, t)}{\partial x}\right)$.

These strengths depend upon previous ones $\beta_{0}$ for $\beta_{0}$ ', but also on the diffusivity contrast between domains $\mathrm{D}^{*}$ and $\mathrm{D} 2$, on the width of domain $\mathrm{D}^{*}(h)$, and on time $(t)$; Appendix B gives the detail of their solutions. Then, as this last image-well does not respect the conditions at boundary L1, it must be imaged about L1 ( $3^{\text {rd }}$ image), which allows evaluating strength coefficients $\alpha_{1}$ and $\beta_{1}$ according to boundary conditions in L1 (Fig. 3b). As the $3^{\text {rd }}$ image does not respect the condition along $\mathrm{L} 2$, it has to be imaged about L2 ( $4^{\text {th }}$ image $)$ and strength coefficients $\beta_{1}$ ' and $\delta_{l}$ should be evaluated according to boundary conditions in L2 (Fig. 3b), and so on. Therefore, each iteration results in a new image-well with a strength evaluated according to boundary conditions at L1 and L2. As the strength of the $\mathrm{n}^{\text {th }}$ image-well depends upon the product of all previous image-strengths, the strengths of each image-well series can be expressed as a combination of arithmetic and geometrical series. The drawdown for an observation well located in D1 is:

$$
\left.\begin{array}{r}
s_{1}(x, y, t)=\frac{Q}{4 \pi T_{1}}\left\{\mathrm{~W}\left(\frac{S_{1}}{4 T_{1} t}\left(x^{2}+y^{2}\right)\right)+\frac{T_{1} \tau_{0}-T^{*} \gamma_{0}}{T_{1} \tau_{0}+T^{*} \gamma_{0}} \mathrm{~W}\left(\frac{S_{1}}{4 T_{1} t}\left([2 a-x]^{2}+y^{2}\right)\right)\right. \\
+\frac{2 T^{*} \gamma_{0} \tau_{0}}{T_{1} \tau_{0}+T^{*} \gamma_{0}} \sum_{n=2,4,6}^{\infty} \frac{2 T_{1}}{T_{1} \tau_{n}+T^{*} \gamma_{n}} \prod_{i=1,3,5}^{n-1} \frac{T^{*} \tau_{i}-T_{2} \gamma_{i}}{T^{*} \tau_{i}+T_{2} \gamma_{i}} \prod_{i=2,4,6}^{n-2} \frac{T^{*} \gamma_{i}^{\prime}-T_{1} \tau_{i}^{\prime}}{T^{*} \gamma_{i}^{\prime}+T_{1} \tau_{i}^{\prime}} \\
\mathrm{W}\left(\frac{S_{1}}{4 T_{1} t}\left([2 a+n h-x]^{2}+y^{2}\right)\right)
\end{array}\right\}
$$

with the second geometrical series (the one up to ' $n-2$ ') valid for $n>2$. 
For a well located in $\mathrm{D}^{*}$, the drawdown is:

$$
\begin{aligned}
s^{*}(x, y, t)=\frac{Q}{4 \pi T^{*}}\left(\frac{2 T^{*} \gamma_{0} \tau_{0}}{T_{1} \tau_{0}+T^{*} \gamma_{0}}\right)\left\{\sum_{n=2,4,6}^{\infty} \prod_{i=1,3,5}^{n-1} \frac{T^{*} \tau_{i}-T_{2} \gamma_{i}}{T^{*} \tau_{i}+T_{2} \gamma_{i}} \prod_{i=2,4,6}^{n-2} \frac{S^{*} \gamma_{i}^{\prime}-T_{1} \tau_{i}^{\prime}}{T^{*} \gamma_{i}^{\prime}+T_{1} \tau_{i}^{\prime}}\left([2 a+n h-x]^{2}+y^{2}\right)\right) \\
\left.+\sum_{n=0,2,4} \prod_{i=1,3,5}^{n-1} \frac{T^{*} \tau_{i}-T_{2} \gamma_{i}}{T^{*} \tau_{i}+T_{2} \gamma_{i}} \prod_{i=2,4,6}^{n} \frac{T^{*} \gamma_{i}^{\prime}-T_{1} \tau_{i}^{\prime}}{T^{*} \gamma_{i}^{\prime}+T_{1} \tau_{i}^{\prime}} \mathrm{W}\left(\frac{s^{*}}{4 T^{*} t}\left([n h+x]^{2}+y^{2}\right)\right)\right\}
\end{aligned}
$$

228

233 with both geometrical series (the ones up to ' $n$-1' and ' $n$ ') valid for $n>1$.

234 with $: \gamma_{0}=\frac{\mathrm{w}\left(\frac{s_{1}}{4 T_{1} t}\left(a^{2}+y^{2}\right)\right)}{\mathrm{w}\left(\frac{s^{*}}{4 T^{*} t}\left(a^{2}+y^{2}\right)\right)} ; \tau_{0}=\frac{\mathrm{e}\left(-\frac{s_{1}}{4 T_{1} t}\left(a^{2}+y^{2}\right)\right)}{\mathrm{e}\left(-\frac{s^{*}}{4 T^{*} t}\left(a^{2}+y^{2}\right)\right)}$

235

$\gamma_{i}=\frac{\mathrm{W}\left(\frac{s^{*}}{4 T^{*} t}\left([a+i h]^{2}+y^{2}\right)\right)}{\mathrm{W}\left(\frac{S_{2}}{4 T_{2} t}\left([a+i h]^{2}+y^{2}\right)\right)} ; \tau_{i}=\frac{\mathrm{e}\left(-\frac{s^{*}}{4 T^{*} t}\left([a+i h]^{2}+y^{2}\right)\right)}{\mathrm{e}\left(-\frac{S_{2}}{4 T_{2} t}\left([a+i h]^{2}+y^{2}\right)\right)}$

236

$\gamma_{i}^{\prime}=\frac{\mathrm{W}\left(\frac{s_{1}}{4 T_{1} t}\left([a+i h]^{2}+y^{2}\right)\right)}{\mathrm{W}\left(\frac{s^{*}}{4 T^{*} t}\left([a+i h]^{2}+y^{2}\right)\right)} ; \tau_{i}^{\prime}=\frac{\mathrm{e}\left(-\frac{s_{1}}{4 T_{1} t}\left([a+i h]^{2}+y^{2}\right)\right)}{\mathrm{e}\left(-\frac{s^{*}}{4 T^{*} t}\left([a+i h]^{2}+y^{2}\right)\right)}$

237

$$
s_{2}(x, y, t)=\frac{Q}{4 \pi T_{2}}\left(\frac{2 T^{*} \gamma_{0} \tau_{0}}{T_{1} \tau_{0}+T^{*} \gamma_{0}}\right)\left\{\begin{array}{c}
\sum_{n=0,2,4}^{\infty} \frac{2 T_{2} \gamma_{n+1} \tau_{n+1}}{T_{2} \tau_{n+1}+T^{*} \gamma_{n+1}} \prod_{i=1,3,5}^{n-1} \frac{T^{*} \tau_{i}-T_{2} \gamma_{i}}{T^{*} \tau_{i}+T_{2} \gamma_{i}} \prod_{i=2,4,6}^{n} \frac{T^{*} \gamma_{i}^{\prime}-T_{1} \tau_{i}^{\prime}}{T^{*} \gamma_{i}^{\prime}+T_{1} \tau_{i}^{\prime}} \\
\mathrm{W}\left(\frac{S_{2}}{4 T_{2} t}\left([n h+x]^{2}+y^{2}\right)\right)
\end{array}\right\}
$$


$\gamma_{n+1}=\frac{\mathrm{W}\left(\frac{s^{*}}{4 T^{*} t}\left([a+(n+1) h]^{2}+y^{2}\right)\right)}{\mathrm{W}\left(\frac{s_{2}}{4 T_{2} t}\left([a+(n+1) h]^{2}+y^{2}\right)\right)} ; \tau_{n+1}=\frac{\mathrm{e}\left(-\frac{s^{*}}{4 T^{*} t}\left([a+(n+1) h]^{2}+y^{2}\right)\right)}{\mathrm{e}\left(-\frac{s_{2}}{4 T_{2} t}\left([a+(n+1) h]^{2}+y^{2}\right)\right)}$

where $\mathrm{W}(u)$ is the exponential integral and $\mathrm{e}(u)$ is the exponential function.

As a result, the strength coefficients depend upon geometrical series that are a function of each domain diffusivity, time, the distance $a$ from the pumping well to the first boundary (L1), and the width $h$ of the strip aquifer (width of $\mathrm{D}^{*}$ ). In each infinite series, the strength coefficient of each image well decreases with distance from both boundaries, and each series converges absolutely. To solve Eqs. 4 to 6, we used an algorithm based on an iterative process, where the number of images is determined when the absolute value of a certain metric given by the $n^{\text {th }}$ computation (of the $\mathrm{n}^{\text {th }}$ becomes negligible (e.g. $10^{-6}$ ). This criterion ensures high computation accuracy.

Note that for the case of time-constant strength coefficients (equal-diffusivity ratio between the compartments), the solutions are the same as those of the appropriate partial differential equation. Solutions of this particular case are given in Appendix (C) for the three-aquifer domains, and, as expected, strength coefficients are identical to the ones given in Anderson (2006), for a solution in steady-state condition.

\subsubsection{Anisotropic case}

Analytical solutions for the three domains can be obtained for the case where the geologic discontinuity ( $\left.\mathrm{D}^{*}\right)$ has an anisotropic transmissivity (or hydraulic conductivity). These solutions are based on the isotropic solutions (Eqs. 4 to 6) and standard transformed coordinate techniques (e.g., Hantush, 1966; Ramey, 1975; Neuman et al., 1984). It is assumed that the main axes of transmissivity in $\mathrm{D}^{*}$ are oriented along the $x$ - and $y$-directions, thus $T_{y}{ }^{*}$ and $T_{x}{ }^{*}$ are parallel and orthogonal to both boundaries, respectively, and $T^{*}=\sqrt{T_{x}^{*} T_{y}^{*}}$. As the pumping well fully penetrates the aquifer (in D1), flow lines are parallel to the bottom of the aquifer. Consequently, the anisotropy of hydraulic conductivity in the vertical plane is not considered.

According to Bear and Dagan (1965) and Anderson (2006), the transformed coordinates in D1 remain unchanged. However, in D2, $x$ coordinate must be shifted to the right along the $x$-axis to account for the transformed width of $\mathrm{D}^{*}$, i.e. $h \sqrt{\frac{T_{y}^{*}}{T_{x}^{*}}}$. Therefore: 
267 in D1,

$$
\dot{x}=x \text { and } \dot{y}=y
$$

268 and in D2,

$$
\dddot{x}=x+h\left(\sqrt{\frac{T_{y}^{*}}{T_{x}^{*}}}-1\right) \text { and } \dddot{y}=y
$$

In $\mathrm{D}^{*}$, the transformed coordinates are more complex because of rotational flow in $\mathrm{D}^{*}$. They

270 are $\ddot{x}=x^{\prime} \sqrt{\frac{T_{y}^{*}}{T_{x}^{*}}}$ and $\ddot{y}=y$, where $x^{\prime}$ is a function of the real-coordinate system that assumes at 271 boundary L1 (i.e. between $\mathrm{D} 1$ and $\mathrm{D}^{*}$ ): $\dot{x}=\ddot{x}=x^{\prime}=a$, and at the second boundary L2 (i.e.

272 between $\mathrm{D}^{*}$ and $\left.\mathrm{D} 2\right): \dddot{x}=\ddot{x}=x^{\prime}=a+h \sqrt{\frac{T_{y}^{*}}{T_{x}^{*}}}$. These re-scaling relationships show that $\mathrm{D}^{*}$ 273 must also be shifted to the right along the $x$-axis to account for the transformed width $h \sqrt{\frac{T_{y}^{*}}{T_{x}^{*}}}$. 274 According to Dewandel et al. (2014), $x^{\prime}$ can be estimated empirically; it is found that $x^{\prime}=$ $275 x+a\left(\sqrt{\frac{T_{x}^{*}}{T_{y}^{*}}}-1\right)$, which gives for $a \leq x \leq a+h$ :

$$
\ddot{x}=\sqrt{\frac{T_{y}^{*}}{T_{x}^{*}}}(x-a)+a
$$

277 The evaluated relationship still depends on the anisotropy ratio in $\mathrm{D}^{*}$ and is linear, which agrees with Baer and Dagan (1965).

279 Drawdown solutions in the transform domains are not re-written as they use isotropic 280 solutions (Eqs. 4, 5, 6), where $h$ is replaced by $h \sqrt{\frac{T_{y}^{*}}{T_{x}^{*}}}$ and $T^{*}$ by $\sqrt{T_{x}^{*} T_{y}^{*}}$. In Eq. 5 (for an observation well in $\mathrm{D}^{*}$ ) $x$ is replaced by $\ddot{x}$, and in Eq. 6 (for a well in D2) $x$ is replaced by $\dddot{x}$, according to the previous re-scaling rules (Eqs. 9 and 10). The $y$ coordinates remain unchanged, as well as the $x$ coordinates in Eq. 4 (for a well in domain D1). Re-scaling of all three domains also satisfies long pumping stages, when drawdown solutions are characterized by straight lines on semi-log plots whose slope values depend on the average transmissivity of domains D1 and D2. These solutions are compared with numerical modelling, particularly the one in $\mathrm{D}^{*}$, in Section 4. Comparisons between the developed solutions and numerical simulations).

\section{Drawdown and flow behaviour at the pumping well}




\subsection{Isotropic case}

As many type curves exist for describing flow behaviour near such a discontinuity (domain $\left.\mathrm{D}^{*}\right)$, some examples are given below to discuss the main flow behaviour characteristics.

Figure 4 shows the result of Eq. 4 at a pumping well of radius $r_{w}\left(x_{w}=y_{w}=\sqrt{2} r_{w}\right)$ using dimensionless time, $t_{D L}=T_{1} t /\left(S_{1} a^{2}\right)$, and dimensionless drawdown, $s_{D}\left(r_{w} / a, t_{D L}\right)=$ $\frac{2 \pi T_{1}}{Q} S_{p w}\left(r_{w}, t\right)$, for the case where $T_{1} / S_{1}=0.1, T_{2} / S_{2}=0.5, T_{1} / T_{2}=20.0, h=5 \mathrm{~m}$. Figure 4 a presents the case where $T^{*} / T_{1}$ varies from $10^{-2}$ to $10^{3}$ with $S^{*} / S_{1}=20.0$, and Figure $4 \mathrm{~b}$ the case where $S * / S_{1}$ varies from $10^{-3}$ to $10^{3}$ with $T * / T_{1}=100.0$. Diffusivity in $\mathrm{D}^{*}$ thus varies between $10^{-2}$ and $10^{3}$. The dimensionless forms of the solutions (Eqs. 4 to 6) are provided as Supporting Information.

A convenient starting point for the analysis of Eq. 4 is the log-log diagnostic plot developed by Bourdet et al. (1983). In this plot, both drawdown $\left(\mathrm{s}_{\mathrm{D}}\right)$ and its derivative $\left(\mathrm{s}_{\mathrm{D}}{ }^{\prime}\right)$ are shown with respect to the natural logarithm of time $\left(\partial s_{D} / \partial \operatorname{Ln}\left(t_{D L}\right)\right)$. Among others, this log-log plot is commonly used for identifying flow regimes during a pumping test (Ehlig-Economides, 1988; Bourdet et al., 1989; Spane and Wurstner, 1993; Renard et al., 2009; Ferroud et al, 2019). For all presented derivative curves in this work, derivatives were computed numerically according to Bourdet's et al. (1989) algorithm.

During the early stages of pumping, when the cone of depression has not yet reached boundary L1 $\left(t_{D L}<0.2\right.$ on Figs. $4 \mathrm{a}$ and b), Eq. 4 is identical to the solution of an infinite homogeneous aquifer (Theis, 1935). For a large enough $t_{D L}$, the condition for which Theis' equation reduces to Cooper-Jacob's (1946) equation, a straight line on a semi-logarithmic plot with a slope $1 / 2$ characterizes dimensionless drawdown. Its logarithmic derivative is constant (value of $1 / 2$ ), reflecting the first infinite-radial flow to the well (Fig. 4). Therefore, for short times, the logarithmic derivative of drawdown will converge to $\partial s / \partial \operatorname{Ln}(t)=Q / 4 \pi T_{1}$.

Once the cone of depression begins to reach boundary L1 $\left(t_{D L}>0.2\right)$, transmissivity and storage-coefficient ratios between the pumped (D1) and the strip (D*) aquifers change the character of the drawdown curves. At that time, the drawdown propagates along boundary L1 and within the strip aquifer. For high $T^{*} / T_{1}$ or $S * / S_{1}$ ratios, the derivative slope tends to -1 , showing that the fault zone acts as a steady-state source (i.e. constant head boundary; Abbaszadeh and Cinco-Ley, 1995, Abbaszadeh et al., 2000). The higher the $T^{*} / T_{1}$ or $S^{*} / S_{1}$ ratios, the more the -1 slope is established and the longer it lasts. Note that this trend generally characterizes a fault zone with infinite hydraulic conductivity near a pumping well 
(Abbaszadeh and Cinco-Ley, 1995, Abbaszadeh et al., 2000; Escobar et al., 2013). However, Fig. $4 \mathrm{~b}$ also shows that a similar trend can be obtained for high $S * / S_{1}$ ratios and not necessarily high $T^{*} / T_{1}$ ratios, as in the previously cited literature. Then, at medium-stages $\left(t_{D L}>10.0\right)$, when the fault begins to drain the whole aquifer system, derivatives follow a near $1 / 4$ slope, which describes a bi-linear flow regime within $D^{*}$, as mentioned in previously cited work. However, when $S * / S_{1}$ ratios are high (>100.0 on Fig. $\left.4 \mathrm{~b}\right)$ the derivative's slope tends to $1 / 2$, describing a linear flow regime within $\mathrm{D}^{*}$. It is also interesting to note that, for intermediate $T^{*} / T_{1}$ ratios (with $T^{*}>T_{1}$ ) or $S^{*} / S_{1}$ ratios, drawdown behaves similarly to naturally fractured media like dual-porosity aquifers (Abbaszadeh and Cinco-Ley, 1995), or dual-permeability media such as multilayer aquifers.

When $T^{*} / T_{1}$ and $S * / S_{1}$ ratios decrease (Figs. $4 \mathrm{a}$ and b), derivative curves rise up, and durations of the -1 derivative slope period and subsequent $1 / 4$ or $1 / 2$ slope decrease (linear flow regimes), showing that $\mathrm{D}^{*}$ is less able to drain the whole aquifer system. In the proposed examples, the derivative may form a hump at the end of the linear flow period within $D^{*}$ $\left(t_{D L}>30\right.$ on Fig. 4 a or 6000 on Fig. 4 b). On Fig. $4 a$, it is the consequence of a decrease in the $T * / T_{1}$ ratio $(<1)$, and on Fig. $4 \mathrm{~b}$ it is the result of a lower diffusivity contrast between domains $\mathrm{D}^{*}$ and D2. The smaller the contrast, the greater the hump, which may cause boundary L1 (Fig. 4a) and L2 (Fig. 4b) to appear temporarily as a no-flow boundary (see blue curves on Fig. 4a).

At late pumping stages $\left(t_{D L}>10^{5}\right.$ on Figs. $4 \mathrm{a}$ and $\left.4 \mathrm{~b}\right)$, drawdown has diffused through the whole domain $\mathrm{D}^{*}$ and propagates significantly in the third domain (D2). This period is characterized by a second radial flow regime, illustrating the overall response of the aquifer system.

During very late stages of pumping (i.e. $t \rightarrow \infty$ or $t_{D L} \rightarrow \infty$ ), all strength coefficients $\gamma_{\mathrm{i}}$ and $\tau_{\mathrm{i}}$ in Eq.4, but also in Eqs. 5 and 6, tend to 1. Therefore, and after rearranging Eq. 4, the logarithmic derivative of the dimensionless drawdown for late-pumping stages leads to:

$$
\operatorname{Lim}_{t_{D L} \rightarrow \infty} \frac{\partial S_{D}}{\partial t_{D L}} \approx\left(\frac{2 T_{1}}{T_{1}+T^{*}}\right)\left\{1+\left(\frac{2 T^{*}}{T_{1}+T^{*}}\right)\left(\frac{T^{*}-T_{2}}{T_{2}+T^{*}}\right) \sum_{n=0,1,2}^{\infty}\left(\frac{T^{*}-T_{2}}{T_{2}+T^{*}}\right)^{n}\left(\frac{T^{*}-T_{1}}{T_{1}+T^{*}}\right)^{n}\right\}
$$

As $\left(\frac{T^{*}-T_{2}}{T_{2}+T^{*}}\right)$ and $\left(\frac{T^{*}-T_{1}}{T_{1}+T^{*}}\right)$ ratios are between -1 and 1 , the series can be regarded as a Taylor series that tends, for $n \rightarrow \infty$, to $\frac{\left(T_{1}+T^{*}\right)\left(T_{2}+T^{*}\right)}{2 T^{*}\left(T_{1}+T_{2}\right)}$. Therefore, the last equation simplifies to 
353

354

355

356

357

358

359

360

361

362

363

364

365

366

367

368

369

370

371

372

373

374

375

376

377

378

379

380

381

382

$\operatorname{Lim}_{t_{D L} \rightarrow \infty} \frac{\partial s_{D}}{\partial t_{D L}} \approx\left(\frac{2 T_{1}}{T_{1}+T_{2}}\right)$, showing that the logarithmic derivative of the dimensionless drawdown depends only on the transmissivities of the pumped aquifer (D1) and of domain D2. Thus, the logarithmic derivative of drawdown, $\partial s / \partial \operatorname{Ln}(t)$, will converge to a constant value inversely proportional to the average transmissivities of D1 and D2, $\frac{\partial s}{\partial \operatorname{Ln}(t)}=$ $Q /\left[2 \pi\left(T_{1}+T_{2}\right)\right]$. This shows that, for late-stage pumping, the drawdown slope does not depend on the transmissivity of the strip aquifer $\left(D^{*}\right.$, representing a fault, another geological discontinuity, or another compartment), but on those of the pumped compartment and of the compartment on the other side of the geological discontinuity. This behaviour agrees with previous work (Abbaszadeh and Cinco-Ley, 1995, Abbaszadeh et al., 2000; Rahman et al., 2003; Escobar et al., 2013).

\subsection{Anisotropic case}

As discussed above, the solution with an anisotropic central compartment ( $\mathrm{D}^{*}$ ) is similar to that for the isotropic case (Eq. 4, $h$ being replaced by $h \sqrt{\frac{T_{y}^{*}}{T_{x}^{*}}}$ and $T^{*}$ by $\sqrt{T_{x}^{*} T_{y}^{*}}$ ). Therefore, drawdown and derivative curves are characterized by a similar behaviour (Fig. 5). During the early-stage pumping $\left(t_{D L}<0.2\right), \partial s_{D} / \partial \operatorname{Ln}\left(t_{D L}\right)=1 / 2$ (or $\left.\partial s / \partial \operatorname{Ln}(t)=Q / 4 \pi T_{1}\right)$ - or the first infinite-acting radial flow when boundary L1 has not been reached by the pumping - and for late-stage pumping, $\partial s_{D} / \partial \operatorname{Ln}\left(t_{D L}\right)$ always tends to $\frac{2 T_{1}}{T_{1}+T_{2}}$ (or $\frac{\partial s}{\partial \operatorname{Ln}(t)}=Q /\left[2 \pi\left(T_{1}+T_{2}\right)\right]$ ), which characterizes the overall response of the aquifer system. However, compared to the isotropic case $\left(T_{x}{ }^{*}=T_{y}{ }^{*}\right.$, curves $T^{*} / T_{l}=100.0$ on Fig. $4 \mathrm{a}$ or $S^{*} / S_{l}=20.0$ on Fig. $\left.4 \mathrm{~b}\right)$, the $T_{y}{ }^{*} / T_{x}{ }^{*}$ ratio increase induces a decrease of the derivative slope, up to -1 for the highest ratios $\left(T_{y} * / T_{x}{ }^{*}>100.0\right)$, because of the increasing transmissivity contrast $\left(T_{y}{ }^{*} / T_{1}\right)$ in a direction perpendicular to the central compartment ( $x$-axis). This shows that the anisotropy increase of transmissivity in $\mathrm{D}^{*}$, increases the capacity of the central compartment to drain the entire system, and thus its capacity to supply water to the pumped D1 compartment. Consequently, at medium-stage bi-linear flow ( $1 / 4$ derivatives slope) or linear flow ( $1 / 2$ derivatives slope), regimes are shifted in time. The higher the $T_{y}{ }^{*} / T_{x}{ }^{*}$ ratio, the greater the offset.

Conversely, a decrease in the anisotropy ratio $\left(T_{y}{ }^{*} / T_{x}{ }^{*}<1.0\right.$, Fig. 5) induces a lower transmissivity contrast between D1 and $\mathrm{D}^{*}\left(T_{y}{ }^{*} / T_{l}\right)$. This reduces both the exchange between domains and the capacity of $\mathrm{D}^{*}$ to drain the whole system. For the lowest contrast 
$\left(T_{y}{ }^{*} / T_{x}{ }^{*}<10^{-2}\right)$, D* may act as a semi-permeable boundary, even though the overall transmissivity value of $\mathrm{D}^{*}$ is still significantly higher than that of $\mathrm{D} 1\left(T^{*} / T_{1}=100.0\right.$, Fig. 5).

\section{Comparison between developed solutions and numerical simulations}

We compared the performance of solutions with transmissivity anisotropy in $D^{*}$ with numerical modelling, to check their accuracy but also to evaluate Eq. 9 required for the drawdown solutions in $\mathrm{D}^{*}$. The numerical modelling was developed with the MARTHE_7.4 CBRGM computer code (Thiéry, 2010, 2015, 2018). MARTHE allows 2D or 3D modelling of flow and mass transfers in aquifer systems, including climatic and human influences. Groundwater flow is computed by a 3-D finite volume approach, to solve the hydrodynamic equation based on Darcy's law and mass conservation. The grid geometry used in the numerical model is a $40 \times 40 \mathrm{~km}$ square grid with a constant-head boundary condition at each side. In the $x, y$ plane, cell size varies from $1 \times 1 \mathrm{~m}$ at the origin (pumping well) up to $500 \times 500 \mathrm{~m}$ near the limits of the model. Vertically, the pumped aquifer is a 100-m-thick layer subdivided into 25 4-m-thick layers. The aquifer is capped by an impermeable layer (no-flow condition), creating a confined condition for the pumped layer.

Several diffusivity ratios between the three domains and widths of the strip aquifer were prescribed to test the isotropic and the anisotropic solutions at various observation-well locations, i.e. in the pumped compartment D1, the strip aquifer $\mathrm{D}^{*}$, and in the right-side compartment D2. Figure 6 shows the results of two of these models for testing the anisotropic solutions. In the model, the pumping well fully penetrates the aquifer and is located at the centre of the grid $(x=0 ; y=0)$ and at $12 \mathrm{~m}(a=12 \mathrm{~m})$ from a 8 -m-wide strip aquifer $(h=8 \mathrm{~m}) . \mathrm{In}$ both cases, transmissivity in the pumped compartment D1, $T_{1}$, is $10^{-2} \mathrm{~m}^{2} / \mathrm{s}$ (hydraulic conductivity $k_{l}=10^{-4} \mathrm{~m} / \mathrm{s}$ ), the storage coefficient $S_{l}$ is $2.0 \times 10^{-2}$ (specific storage $S s_{l}=2 \times 10^{-4} \mathrm{~m}^{-}$ ${ }^{1}$ ) and the transmissivity and storage coefficient of the right-hand side compartment (D2), $T_{2}$, is $5 \times 10^{-3} \mathrm{~m}^{2} / \mathrm{s}\left(k_{2}=5 \times 10^{-5} \mathrm{~m} / \mathrm{s}\right)$ and $S_{2}$ is $10^{-3}\left(S s_{2}=10^{-5} \mathrm{~m}^{-1}\right)$, respectively. Only the properties of the strip aquifer $\left(\mathrm{D}^{*}\right)$ differ, although the $T_{y}^{*} / T^{*}{ }_{x}$ anisotropy ratio is the same at 10.0. In Model $1, T^{*}$ is $10^{-1} \mathrm{~m}^{2} / \mathrm{s}\left(k^{*}=10^{-3} \mathrm{~m} / \mathrm{s}\right)$ and $S^{*}$ is $10^{-1}\left(S s^{*}=10^{-3} \mathrm{~m}^{-1}\right)$, and in Model 2, $T^{*}$ is $3 \times 10^{-3} \mathrm{~m}^{2} / \mathrm{s}\left(k^{*}=3 \times 10^{-5} \mathrm{~m} / \mathrm{s}\right)$ and $S^{*}$ is $2 \times 10^{-2}\left(S s^{*}=2 \times 10^{-4} \mathrm{~m}^{-1}\right)$. Thus, in Model 1 the strip aquifer is the most transmissive and capacitive of the whole domain, while it is the least transmissive and the least capacitive in Model 2. For the simulations, a constant pumping rate 
of $Q=1.11 \times 10^{-2} \mathrm{~m}^{3} / \mathrm{s}\left(40 \mathrm{~m}^{3} / \mathrm{h}\right)$ was set up for up to 700 days (about $10^{6} \mathrm{~min}$ ). In this context, the model's boundaries were not reached, and the aquifer remained saturated.

Figures $6 \mathrm{a}$ and $\mathrm{b}$ compare the results of numerical modelling with analytically computed drawdown values. As shown on the figures, drawdown values and derivatives computed with the proposed solutions (Eqs. 4 to 6 with the proposed re-scaling rules of Eqs. 7 to 9), for observation wells in the pumped aquifer (D1; curves A to D on figures), for the ones in the strip aquifer ( $\mathrm{D}^{*}$; curves $\mathrm{E}$ and $\mathrm{F}$ ) and for the ones in the right-side aquifer (D2; curves $\mathrm{G}$ and $\mathrm{H}$ ), perfectly match the values from numerical modelling. The root mean square error (RMSE) was calculated for each numerical-analytical comparison of drawdown values (see inserted tables on Figures 6a and 6b). RMSE values range between $1.4 \times 10^{-3}$ and $1.7 \times 10^{-2} \mathrm{~m}$, showing that the proposed analytical solutions agree with the numerical modelling, a good indication of their accuracy.

\section{Flow along and through boundaries $\mathrm{L} 1$ and $\mathrm{L} 2$}

As mentioned in earlier studies, flow through and across a fracture plane or geological discontinuity (domain $D^{*}$ ) is complex, and may be locally reversed (Fig. 7), particularly where the fault-transmissivity is higher than that of other compartments (Abbaszadeh and Cinco-Ley, 1995, Abbaszadeh et al., 2000; Rahman et al., 2003). The aim of this section is to propose analytical solutions of such flows, and to highlight their spatial and transient evolutions under different diffusivity contrasts $\left(T_{1} / S_{1} \neq T^{*} / S^{*} \neq T_{2} / S_{2}\right)$. The dimensionless forms of the following solutions are provided as Supporting Information.

\subsection{Analytical solutions for flows through L1 and L2}

Analytical solutions for flow through both boundaries can be derived from Eqs. 4 to 6 for an isotropic central compartment $\left(\mathrm{D}^{*}\right)$, and with re-scaling rules presented in section 2.4.2. for the anisotropic case (Eqs. 7 to 9 ).

The solutions for flow are normalized with respect to the pumping flowrate $Q$, thus representing the fraction of $Q$ that flows through L1 and L2 $\left(\frac{\Delta Q_{L 1}}{Q} ; \frac{\Delta Q_{L 2}}{Q}\right)$. Along boundary L1 ( $x=a$; between $\mathrm{D} 1$ and $\mathrm{D}^{*}$ ), according to Eq. 4 and for the anisotropic case, the solution is: 


$$
\left.\begin{array}{rl}
\frac{\Delta Q_{L 1}(y, t)}{Q}=\frac{T_{1}}{Q} & \frac{\partial s_{1}(a, y, t)}{\partial x} \\
= & \frac{T^{*} \gamma_{0}}{\pi\left(T_{1} \tau_{0}+T^{*} \gamma_{0}\right)}\left\{\frac{a}{a^{2}+y^{2}} e^{-\frac{s_{1}}{4 T_{1} t}\left(a^{2}+y^{2}\right)}\right. \\
& -\tau_{0} \sum_{n=2,4,6}^{\infty} \frac{2 T_{1}}{T_{1} \tau_{n}+T^{*} \gamma_{n}} \prod_{i=1,3,5}^{n-1} \frac{T^{*} \tau_{i}-T_{2} \gamma_{i}}{T^{*} \tau_{i}+T_{2} \gamma_{i}} \prod_{i=2,4,6}^{n-2} \frac{T^{*} \gamma_{i}^{\prime}-T_{1} \tau_{i}^{\prime}}{T^{*} \gamma_{i}^{\prime}+T_{1} \tau_{i}^{\prime}} \\
& \left(\frac{n h^{*}+a}{\left[a+n h^{*}\right]^{2}+y^{2}}\right) e^{-\frac{s_{1}}{4 T_{1} t}\left(\left[a+n h^{*}\right]^{2}+y^{2}\right)}
\end{array}\right\}
$$

and for flow along boundary L2 ( $x=a+h$; between $\mathrm{D}^{*}$ and D2), according to Eq. 6 and for the anisotropic case, the solution is:

$$
\begin{aligned}
& \frac{\Delta Q_{L 2}(y, t)}{Q}=\frac{T_{2}}{Q} \frac{\partial s_{2}(a+h, y, t)}{\partial x}
\end{aligned}
$$

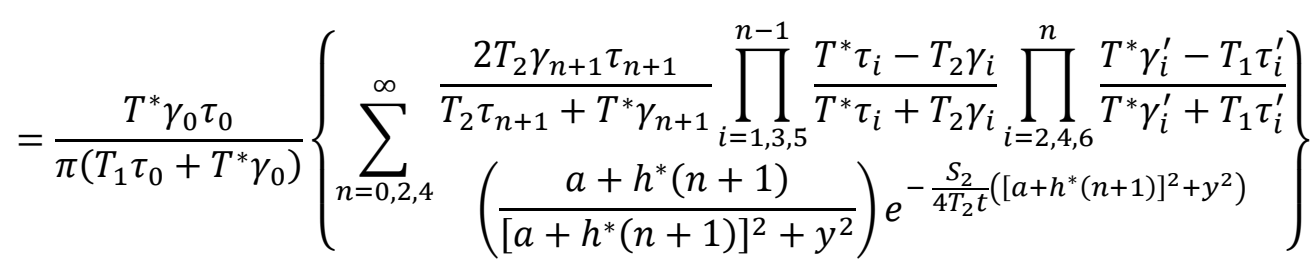

446 where $h^{*}=h \sqrt{\frac{T_{y}^{*}}{T_{x}^{*}}}, T^{*}=\sqrt{T_{x}^{*} T_{y}^{*}}$, and where coefficients $\gamma$ and $\tau$ are determined from Eqs. 4 to $447 \quad 6\left(h\right.$ is replaced by $h \sqrt{\frac{T_{y}^{*}}{T_{x}^{*}}}$, and $T^{*}$ by $\left.\sqrt{T_{x}^{*} T_{y}^{*}}\right)$. Note that Eq. 11 and Eq. 12 can also be obtained from Eq. 5 (domain $D^{*}$ ) at the corresponding boundaries.

\subsection{Flux profile along $L 1$ and $L 2$}

451 Equations 11 and 12 are complex functions whose behaviour was explored through numerical experiments. Figures $8 \mathrm{a}$ and $\mathrm{b}$ show the flow profile along both boundaries (i.e. along the $y$ axis, with $y \geq 0$ both solutions being symmetrical about the $x$-axis) after 21 days of pumping $454\left(t=3 \times 10^{4} \mathrm{~min}\right.$ and $\left.Q=1 \mathrm{~m}^{3} / \mathrm{h}\right)$. For this experiment, the pumping well is located at $10.0 \mathrm{~m}$ from 455 a 5-m-wide strip aquifer ( $a=10.0 \mathrm{~m}$ and $h=5.0 \mathrm{~m})$. In all cases, the hydraulic properties in D1 456 are identical $\left(T_{1}=10^{-3} \mathrm{~m}^{2} / \mathrm{s} ; S_{1}=5 \times 10^{-3}\right)$. For curves A to F, the properties of D2 are identical 
to those of D1 $\left(T_{1}=T_{2} ; S_{1}=S_{2}\right)$, D* is isotropic but its properties differ, $T^{*}$ varies from $2 \times 10^{-4}$ to $2 \times 10^{-2} \mathrm{~m}^{2} / \mathrm{s}$ and $S^{*}$ from $10^{-3}$ to $6 \times 10^{-1}$, making compartment $\mathrm{D}^{*}$ both the most or the least transmissive, or the most and the least diffusive aquifer. Curve $\mathrm{G}$ is similar to $\mathrm{C}$, but $\mathrm{D} 2$ is the least transmissive, and storativity is the least $\left(T_{2}=10^{-4} \mathrm{~m}^{2} / \mathrm{s} ; S_{2}=10^{-3}\right)$. Curve $\mathrm{H}$ differs from $\mathrm{G}$ only because $\mathrm{D}^{*}$ is anisotropic in transmissivity $\left(T_{y} * / T_{x} *=50.0\right)$.

Analysis of these curves shows that, as mentioned in earlier studies (Abbaszadeh and CincoLey, 1995, Abbaszadeh et al., 2000; Rahman et al., 2003), the flow through boundary L1 is mainly from the compartment $\mathrm{D}^{*}$ to D1. Locally, however, it can also be reversed (from D1 to $\mathrm{D}^{*}$ ) when the central compartment $\mathrm{D}^{*}$ becomes the most transmissive aquifer (Fig. 8a, curves A, B, C, G and H). This flow reversal indicates that, at a certain distance along the $y$ axis (or from the pumping well) and after a certain duration of pumping, the hydraulic gradient at the boundary between D1 and $\mathrm{D}^{*}$ is reversed. This implies that streamlines are reversed, because drawdown within the central compartment propagates faster than in the surrounding compartments. Such behaviour stems from the higher transmissivity in $\mathrm{D}^{*}$, but not necessarily because of a higher diffusivity (curves: A, B). For curve E, D* is the most diffusive, but reversed flow is absent. Curve A presents the equal diffusivity ratio case in which flow reversal occurs. Regarding the storativity $\left(S^{*}\right)$, the higher the value, the greater the reversed flow (curves: A, B, C). When compartment D2 on the right-side is the least transmissive (curves $\mathrm{G}$ and $\mathrm{H}$ ), the flow in $\mathrm{D}^{*}$ and therefore the reversed flow (D1 to $\mathrm{D}^{*}$ ) increase, and an increase in transmissivity anisotropy of $\mathrm{D}^{*}\left(T_{y}{ }^{*}>T_{x}{ }^{*}\right)$ enhances the flow reversal (curve $\mathrm{H}$ ). When D2 is the least transmissive, reversed flow may occur even if $T^{*} \leq T_{1}$, but with $T^{*} \geq T_{2}$ (not shown on the figure), the increase in anisotropy of $\mathrm{D}^{*}\left(T_{y}{ }^{*}>T_{x}{ }^{*}\right)$ will still increase such flow. Logically, when $\mathrm{D}^{*}$ is the least transmissive, no reversed flow will occur (curves: D, E, F), as well as when $T_{2}$ becomes the most transmissive aquifer (not shown on the figure).

Other tests concerned the distance between the pumping well and L1 (a), and the width of the central compartment $(h)$. They showed that, regarding distance ' $a$ ', the greater the distance, the greater the influence of pumping on the pumped compartment (D1), and therefore the less on $\mathrm{D}^{*}$ and $\mathrm{D} 2$. Therefore, logically, flows along the two discontinuities are reduced as ' $a$ ' increases. An increase in the width of the central compartment $(h)$ induces an increase in the lateral transmissivity of the central compartment, perpendicular to the $x$-axis, which facilitates the propagation of drawdown in this direction, to the detriment of the $y$-axis. Consequently, 
489

490

491

492

493

494

495

496

497

498

499

500

501

502

503

504

505

506

507

508

509

510

511

512

513

514

515

516

517

518

519

drawdown within the aquifer of the central strip aquifer propagates less rapidly, reducing the reversal hydraulic gradient between D1 and D*, and therefore the reversed flow.

Flow along boundary L2 (between D* and D2) is less complex as it is always positive, from D2 to D* (Fig. 8b). It increases when $\mathrm{D}^{*}$ is the least transmissive compartment (curves: D, E, $\mathrm{F}$ ), and decreases when $\mathrm{D}^{*}$ is the most transmissive or anisotropic (with $T y^{*}>T x^{*}$ ) compartment (curves: A, B, C, H), or when D2 is the least transmissive (curves $\mathrm{G}$ and $\mathrm{H}$ ). Logically, when D2 is the most transmissive compartment, flow increases (not shown on the figure).

\subsection{Time-variation of flux along L1 and L2}

Figures $9 \mathrm{a}$ and $\mathrm{b}$ show the evolution of flow profiles through both boundaries for case $\mathrm{H}$ on Figure 8 (the anisotropic case $T_{y}^{*} / T_{x}^{*}=50.0$ ), at time of pumping $t=1,7,30,200,500,3 \times 10^{3}$, $3 \times 10^{4}$ and $10^{8} \mathrm{~min}$. Up until $30 \mathrm{~min}$, the flow at boundary L1 is only from compartment $\mathrm{D}^{*}$ to D1, as the hydraulic gradient between D1 and D* is always positive. During this period, particularly from about $2 \mathrm{~min}$, when drawdown begins to reach L1, to $30 \mathrm{~min}$, drawdown does not propagate more rapidly in $\mathrm{D} 1$ than in $\mathrm{D}^{*}$. From $t=30 \mathrm{~min}$ the flow reversal starts, as the drawdown begins to propagate faster in $\mathrm{D}^{*}$. The location of the point of reversed flow into/from $\mathrm{D}^{*}$, increases slightly with time. At $t=200 \mathrm{~min}$ the reversal point is at about $48.0 \mathrm{~m}$, and then converges to about $58 \mathrm{~m}\left(y=58.0 \mathrm{~m}\right.$ at $\left.t=10^{8} \mathrm{~min}\right)$. Along L2, the flow from D2 to $\mathrm{D}^{*}$ increases with time, particularly for the smallest values of $y(0 \leq y \leq 150-200 \mathrm{~m} ; t=1,7$ and $30 \mathrm{~min})$. Then, it flattens for longer time values, but total flow increases significantly. In fact, after 200 min, linear to bi-linear flow regimes start to occur in $\mathrm{D}^{*}$ (Fig. 10c), which means that $\mathrm{D}^{*}$ begins to drain the two surrounding aquifers (D2 and D1).

The precise assessment of flow along L1 (Eq. 11; Figs. 7a and 8a) is a challenging task. It requires separation of the two flow components, the one from $\mathrm{D}^{*}$ to $\mathrm{D} 1$ (positive flow), and the one from D1 to $\mathrm{D}^{*}$ (negative or reversed flow). This implies separating the positive and negative values of the calculation of Eq. 11. The flow at each time $t$ can be calculated by integrating Eq. 11 along the $y$-axis at the appropriate interval. For flow from $\mathrm{D}^{*}$ to D1, the solution is:

$\frac{\Delta Q_{L 1}(t)}{Q}=2 \int_{0}^{y_{f}} \frac{\Delta Q_{L 1}}{Q} d y$

\footnotetext{
and the one from D1 to D* (flow reversal), is:
} 
520

$\frac{\Delta Q_{L 1}(t)}{Q}=2 \int_{y_{f}}^{\infty} \frac{\Delta Q_{L 1}}{Q} d y$

where $\frac{\Delta Q_{L 1}}{Q}$ is given by Eq. 11 and $y_{f}$ is the location of the point of reversed flow into/from compartment $\mathrm{D}^{*}$ onto the $y$-axis. However, no formal solution of the roots of Eq. 11 was found, and they were evaluated numerically using the Newton-Raphson method.

For flow along L2, entering compartment D* from D2, Eq. 12 has to be integrated along L2 ($\infty<y<\infty)$, which gives:

$\frac{\Delta Q_{L 2}(t)}{Q}=2 \int_{0}^{+\infty} \frac{\Delta Q_{L 2}}{Q} d y$

527 where $\frac{\Delta Q_{L 2}}{Q}$ is given by Eq. 12 .

528

Note that all integrals in Eqs. 13 to 15 are multiplied by two, to account for symmetrical properties of equations about the $x$-axis. Net flow from Domain $\mathrm{D}^{*}$ is obtained by subtracting Eq. 13 from both Eqs. 14 and 15.

Figure 10a shows the variations of the various flow components over time, for the anisotropic example given in Fig. $9\left(T_{y}^{*} / T_{x}{ }^{*}=50.0\right)$ and for the case where the compartment $\mathrm{D}^{*}$ is isotropic $\left(T^{*} / T_{x}^{*}=1.0\right.$; all other parameters remaining unchanged). Figure 10b presents the net flow from the strip-aquifer D* (net flow=Eq. 13-[Eq. 14+Eq. 15]). Figure 10c shows the corresponding drawdowns and their derivatives at the pumping well. Flow entering D1 from $D^{*}$, or the one entering $D^{*}$ from D1 (flow reversal), increases sharply once drawdown begins to propagate significantly in $\mathrm{D}^{*}$ (-1 or negative slope on derivatives). Then, once the bi-linear to linear flow regime is established in $\mathrm{D}^{*}(t>100 \mathrm{~min}$; Fig. 10c), and drawdown propagates in the right-side compartment (D2), the flow along L1 increases and then slows down, almost stabilizing over long times when the whole system responds to pumping (second radial flow regime). The contribution of the strip-aquifer to compartment D1 varies over time (net flow, Fig. 10b) according to the various flow components. It first increases rapidly due to the contribution of $\mathrm{D}^{*}$ to $\mathrm{D} 1$ (positive flow) and then, once the feature begins to drain the system, it decreases as reversed flow and flow from D2 increase. Logically, an increase of the anisotropy ratio in $\mathrm{D}^{*}$ increases the net contribution of $\mathrm{D}^{*}$.

\section{Extension of the proposed theory to a well intersecting and pumping a vertical} fracture of finite length located near an infinite fault 
We propose drawdown solutions for the case of a well intersecting and pumping a vertical fracture of finite length, $2 l$, making an angle $\alpha$ with the $x$-axis (Fig. 1b; Fig. 11) near an infinite vertical discontinuity. They are based on the drawdown solutions for the three compartments developed above for the isotropic and anisotropic cases. The pumping well is located at the centre of the fracture, at a distance $a$ from L1. The fracture fully penetrates the aquifer, and should not cross domain $\mathrm{D}^{*}$ (i.e. $l \cos \alpha \leq a$ ). Assuming that the pumping rate $Q$ is uniformly distributed along the fracture, i.e. the rate of pumping per unit length of the fracture is $q(x, y)=Q / 2 l$, according to Dewandel et al. (2018), drawdown solutions can be obtained by integrating the above solutions along the fracture axis. Solutions for the three domains then take the following general form:

$s_{\text {frac }}(x, y, t)=\int_{-l}^{+l} s(x, y, t) d \vartheta$

where $s(x, y, t)$ corresponds to Eqs. 4,5 or 6 for the isotropic case, which, combined with Eqs. 7, 8 or 9 gives the solutions for the anisotropic case (or $T_{y}^{*} / T^{*} \neq 1$ ). Note that for the particular case where the distance of the pumped fracture to L1 is infinite $(a \rightarrow \infty$; i.e. there is only one aquifer system, D1), Eq. 16 corresponds exactly to a known analytical solution (Gringarten et al. (1974), their Eq. 20) for drawdown in a well pumping a vertical fracture with uniform flux distribution that fully penetrates the aquifer (Dewandel et al., 2018).

The integral in Eq.16 can be evaluated numerically with the Gauss-Legendre quadrature, as done here, or evaluated using a discretized form of Eq. 16 by dividing the fracture into small elements and placing the appropriate line-source solution at the centre of each segment (Dewandel et al., 2018, their Eq. 7).

\subsection{Drawdown and flow behaviours at the pumping well}

Figure 11 presents the result of Eq. 16 for a pumping well of radius $r_{w}$ intercepting a fracture parallel to domain $\mathrm{D}^{*}$ (i.e. parallel to the $y$-axis, $\alpha=90^{\circ}$ ). Dimensionless time according to fracture length, $t_{D f}=T_{1} t /\left(S_{1} l^{2}\right), \quad$ and dimensionless drawdown, $s_{D f}\left(a / l, t_{D f}\right)=\frac{2 \pi T_{1}}{Q} s_{p w f}\left(r_{w}, t\right)$, are used for presenting the case where $T_{1} / S_{1}=0.1$, $T^{*} / S^{*}=T_{2} / S_{2}=0.5, T^{*}{ }_{y} / T_{x}^{*}=10.0, T^{*} / T_{1}=100.0 ; T_{1} / T_{2}=20.0, h=5 \mathrm{~m}$, and $a / l$ ratios varying from 1 to 10. This setting describes the behaviour of a fracture with increasing distance from boundary L1. 
At the start of pumping, the flow is linear (half-unit slope of derivative curves) and corresponds to flow from aquifer D1 to the fracture intersected by the pumping well. For intermediate pumping stages, the derivative curves may describe the first infinite-acting radial flow, when both the boundary L1 has not yet been reached by pumping and the fracture is far enough from L1, $a / l>4$. For this case, $\partial s_{D f} / \partial \operatorname{Ln}\left(t_{D f}\right)=1 / 2$ or $\left.\partial s_{f r a c} / \partial \operatorname{Ln}(t)=Q / 4 \pi T_{1}\right)$. Then, once the cone of depression begins to reach boundary L1, the derivative slope decreases, and may tend to -1 when the half-fracture size is close to the distance between the centre of the fracture and L1 $(a / l \leq 3)$. This shows that $\mathrm{D}^{*}$ acts temporarily as a steady-state source. At times $t_{D f}>10.0$ derivatives follow a near $1 / 4$ slope, describing the earlier-mentioned bi-linear flow regime within domain $\mathrm{D}^{*}$. As for the case of pumping in a well (without fracture), the derivative slope may also tend to $1 / 2$ when $S * / S_{1}$ ratios are high (linear flow regime within $\left.\mathrm{D}^{*}\right)$. For late pumping stages $\left(t_{D f}>2.10^{5}\right.$ in Fig. 11), the drawdown has diffused through the whole domain $\mathrm{D}^{*}$ and propagates significantly into the right-side aquifer (domain D2), indicating that $D^{*}$ drains the whole aquifer system. A second radial flow regime is encountered and characterizes the overall response of the aquifer system, the derivative always tending to $\frac{2 T_{1}}{T_{1}+T_{2}}$ (or $\frac{\partial s_{\text {frac }}}{\partial \operatorname{Ln}(t)}=Q /\left[2 \pi\left(T_{1}+T_{2}\right)\right]$ ), as in previous solutions (see section 3., above).

\subsection{Flow along and through boundaries $L 1$ and $L 2$}

As done previously for pumping in a well (without fracture), flow along and across both boundaries L1 and L2 can also be computed using the same procedure as described before (section 5.). Figures 12 and 13 show examples of flow profiles along L1 and L2 at $t=3 \times 10^{4} \mathrm{~min}$, and time-variations of fluxes along L1 and L2, respectively, for pumping in a 20-m-long fracture $(2 l=20 \mathrm{~m})$ either parallel $\left(\alpha=90^{\circ}\right)$, perpendicular $\left(\alpha=0^{\circ}\right)$, or making a $45^{\circ}$ angle with compartment $\mathrm{D}^{*}\left(\alpha=45^{\circ}\right)$. In all cases, the aquifer properties in all three compartments are identical to case $\mathrm{H}$ in Fig. $8\left(T_{l}=10^{-3} \mathrm{~m}^{2} / \mathrm{s}, S_{l}=5 \times 10^{-3}, T^{*}=2 \times 10^{-2} \mathrm{~m}^{2} / \mathrm{s}\right.$, $\left.S^{*}=10^{-2}, T^{*} y / T^{*} x=50.0, T_{2}=10^{-4} \mathrm{~m}^{2} / \mathrm{s}, S_{2}=10^{-3}, h=5 \mathrm{~m}, a=10 \mathrm{~m}, Q=1 \mathrm{~m}^{3} / \mathrm{h}\right)$. The results are also compared to the case where the well that is pumped does not intersect a fracture.

For pumping in a fracture, flow profiles along both boundaries L1 and L2 have a similar shape compared to the case of pumping in a well, and are logically symmetric to the $y$-axis when the fracture is symmetric to the $y$-axis $\left(\alpha=0^{\circ}\right.$ and $90^{\circ}$; Fig. 12). Compared to pumping in a well, flow along boundary L1 (Fig. 12a) is higher near the $x$-axis $(x=0)$ when the fracture 
is perpendicular to $\mathrm{D}^{*}\left(\alpha=0^{\circ}\right)$, and is logically less important when it is parallel to it $\left(\alpha=90^{\circ}\right)$. When the fracture makes a secant angle with $\mathrm{D}^{*}\left(\alpha=45^{\circ}\right)$, maximum flow shifts to the side where the fracture is closer to boundary L1 (here, to the right). Reversed flow (from D1 to $\left.\mathrm{D}^{*}\right)$ is similar in all cases, including the pumping well case, as the reversal point is far from the fracture, at about $50 \mathrm{~m}$.

Concerning flow along boundary L2 (Fig. 12b), the same remarks apply, except that for the fracture cases flux distribution is characterized by a sharp distribution almost centred along the $x$-axis (near $\mathrm{x}=0$ ), and is locally higher than that for the well case. This shows that pumping in a fracture concentrates flow in a larger area, and then solicits more compartment D2 near the fracture.

When pumping a fracture, time-variations of flow show similar behaviour to that of the pumping well case (Fig. 13a). In particular, flow reversal is almost identical for all cases. The main difference compared to the pumping well case occurs when the fracture makes a secant angle with $\mathrm{D}^{*}\left(\alpha=0\right.$ and $\left.45^{\circ}\right)$, forcing $\mathrm{D}^{*}$, but also $\mathrm{D} 2$, to react more rapidly, even at early stages during the linear flow caused by pumping in the fracture (Fig. 13c). However, for late pumping stages, the flow from $\mathrm{D}^{*}$ to $\mathrm{D} 1$ is less in the cases considering a fracture when compared to the pumping well case. This difference stems from the larger pumped area that facilitates the reaction of D1 near the pumped fracture. Consequently, the net flow from compartment $\mathrm{D}^{*}$ to D1 (Fig. 13b) is less important when pumping is done through a fracture.

\section{Conclusions}

New analytical solutions for drawdown are proposed for a pumping well, and for a well intersecting and pumping a vertical fracture of finite length, near an infinite vertical fault zone or another vertical geological discontinuity (vein, dyke, strip aquifer) with finite width, finite storativity, and finite - and possibly anisotropic - hydraulic conductivity. Consequently, the solutions proposed can relate to a relatively large set of hydrogeological situations. However, the dip of the structure must be close to vertical and long enough (with regard to the pumping duration) to be considered as infinite for a good use of the solutions (see Fig. 1).

The solutions are based on an unconventional application of well-image theory, without limitation on the diffusivity contrast between the aquifer compartments, and considering flow transience within the fault. Solutions were developed for the drawdown in three aquifer 
compartments, the pumped compartment, the one within the fault zone, and the compartment on the other side of the fault. The solutions are good approximations of the corresponding partial differential equations, and comparison with numerical simulations showed high accuracy.

Drawdown and flow regimes in the pumping well were analysed in various configurations and, overall, are similar to previous studies, especially when the fault zone is strongly permeable and anisotropic. In the last case and once the cone of depression reaches the fault, the slope of the logarithmic derivative of drawdown in the pumping well tends to -1 , showing that the fault temporarily acts as a steady-state source. Later, when the fault begins to drain the whole aquifer system, the derivative follows typical $1 / 4$ or $1 / 2$ slopes, depending upon the contrast in aquifer properties that describe bi-linear to linear flow regimes within the fault zone. For the late stages of pumping, the derivative forms a second radial flow regime that depends upon the average transmissivities of the two external aquifer compartments, but not on the fault zone. The first radial flow is established at an early stage, before the cone of depression reaches the fault zone.

This application of image-well theory fits the need for other well functions, which should be derivable on $x$ to get mathematical expressions of strength coefficients. Therefore, drawdown solutions were developed for a well intersecting and pumping a vertical fracture of finite length located near the same infinite vertical fault zone. In terms of flow regimes, behaviour was similar to the pumping well case, except for early pumping stages when a first linear-flow regime defines the response of the pumped vertical fracture. We also believe that other solutions can be derived for a partially penetrating well, or a partially penetrating fracture pumped by a well, located near a 3-D anisotropic fault using the Hantush and Hantush leakywell functions (Hantush, 1964, 1966; Dewandel et al., 2014). A 3-D geometry of the pumped fracture could be considered as well.

An interesting point of the proposed solutions is the possibility to derive transient-flow solutions along both sides of the fault zone, and thus net transient flow from the fault itself. Depending on the contrast in aquifer parameters between the three compartments, flow reversal between the fault and the pumped aquifer occurs, as found in previous work, when the fault zone is the most permeable. We show that net flow from the fault into the pumped aquifer increases rapidly during the early pumping stage due to contribution of the fault zone, and then, once the fault begins to drain the system, it decreases as reversed flow and flow from the opposite-side aquifer increase. Logically, an increasing anisotropy of the fault zone 
675 increases the net contribution of the fault. When the pumping takes place through a vertical

684

685

686

687

688

689

690

691

692

693

694

695

696

697

698

699

700

701

702

703 fracture near a fault zone, net flow is less important because the fracture increases the reaction of the pumped compartment, compared to the fault zone and the opposite-side compartment. Furthermore, all results show that the net flow contribution is characterized by strong timevariation that stabilizes by long pumping stages. This may influence the quality of the pumped water, especially when the water quality of the fault zone is different from that where the well is located. Future work should focus on such flow computations in an experimental site, using geochemical data for assessing the origin of water (or fluid) when pumping a well, or one that intersects and pumps a fracture near a vertical geological discontinuity.

\section{Acknowledgements}

The authors are grateful for a research-sponsorship from BRGM (France) and from the Dem'Eaux Thau Research Project, co-funded by the French Water Agency of Rhône Mediterranean \& Corsica (AEMRC), Balaruc-les-Bains city, the Syndicat Mixte du Bassin de Thau (SMBT), Montpellier Méditerranée Métropole, European Funds for Regional Development, the French Ministry for Research, and Occitanie Region (CPER). The authors thank Francisco J. Valdes-Parada (Editor of the journal) and two anonymous reviewers for their useful comments and remarks. The authors are grateful to Dr. H.M. Kluijver for revising the final version of the English text.

\section{References}

Abbaszadeh M.D., Cinco-Ley H., 1995. Pressure transient behavior in a reservoir with a finite-conductivity fault. SPEFE March 1999; Trans., AIME, , 26-32.

Abbaszadeh M., Asakawa K., Cinco-Ley H., Arihara N., 2000. Interference testing in reservoirs with conductive faults or fractures. SPE Reservoir Eval. \& Eng. 3 (5), 426-434.

Althawad, M.S., 2016. Semi-analytical solution to a fractured well in an asymmetric reservoir with a finite conductivity fault. $\mathrm{PhD}$ Thesis in Petroleum Engineering. Heriot-Watt University, Institute of Petroleum Engineering, Edinburgh U-K, May 2016. 189 p.

Anderson, E.I., 2000. The method of images for leaky boundaries. Wat. Res., 23, 461-474. 
Anderson, E.I., 2006. Analytical solutions for a flow to a well through a fault. Adv. in Wat. Ress., 29, 1790-1803.

Bear J. and G. Dagan, 1965. The relationship between solutions of flow problems in isotropic and anisotropic soils. J. of Hydrology, 3, 88-96.

Bense VF, van Balen RT, De Vries JJ, 2003. The impact of faults on the hydrogeological conditions in the Roer Valley Rift System: an overview. Netherlands J. Geosci; 82(1):317-20.

Bixel, H.C., Larkin B.K., van Poollen H.K., 1963. Effect of linear discontinuities on pressure build-up and drawdown behavior. J. of Petr. Techn, August 1963, 885-895.

Bourdet, D., Whittle T.M., Dougals, A.A., Pirard V.M., 1983. A new set of type curves simplifies well test analysis, World Oil., 95-106, Gulf Publishing Co., Houston.

Bourdet D., Ayoud J.A., Prirard Y.M., 1989. Use of pressure derivative in well-test interpretation. SPE, 293-302.

Boussila, A.K., Taib, D., Owayed, J., 2003. Pressure behavior of well near a leaky boundary in heterogeneous reservoirs. SPE 80911, https://doi.org/10.2118/80911-MS

Bruggeman, G.A., 1999. Analytical Solutions of Geohydrological Problems. Developments in Water Science 46, Elsevier, The Netherlands, 959 p.

Butler, J.J. Jr., Liu W.Z., 1991. Pumping tests in non-uniform aquifers-The linear strip case. J. of Hydrol., 128, 69-99.

Caine JC, Evans JP, Forster CB. Fault zone architecture and permeability structure. Geology 1996;24(11):1025-8.

Cooper, H.H. and C.E. Jacob, 1946. A generalized graphical method for evaluating formation constants and summarizing well field history, Am. Geophys. Union Trans., vol. 27, pp. 526534.

Dewandel, B., Lachassagne, P., Zaidi, F.K., Chandra, S., 2011. A conceptual hydrodynamic model of a geological discontinuity in hard rock aquifers: example of a quartz reef in granitic terrain in South India. J. of Hydrol., 405, 474-487.

Dewandel, B., Maréchal, J.C., Bour, O., Ladouche, B., Ahmed, S., Chandra, S., Pauwels H., 2012. Upscaling and regionalizing hydraulic conductivity and efficient porosity at watershed scale in crystalline aquifers. J. of Hydrol., 416-417, 83-97. 
733 Dewandel B., Aunay B., Maréchal J.C., Roques C., Bour O., Mougin B. and L. Aquilina, 734 2014. Analytical solutions for analysing pumping tests in a sub-vertical and anisotropic fault zone draining shallow aquifers. J. of Hydrology, 509, 115-131.

Dewandel B., S. Lanini, P. Lachassagne, J.-C. Maréchal, 2018. A generic analytical solution for modelling pumping tests in wells intersecting fractures. J. of Hydrology, 559, 89-99, https://doi.org/10.1016/j.jhydrol.2018.02.013.

Ehlig-Economides, C.A., 1988. Use of the pressure derivative for diagnosing pressuretransient behavior. J. Petrol. Technol. (October), 1280-1288.

Escobar, F. H., Martínez, J. A. \& Montealegre-Madero, M., 2013. Pressure transient analysis for a reservoir with a finite-conductivity fault. CT\&F - Ciencia, Tecnología y Futuro, 5(2), 518.

Fenske, P.R., 1984. Unsteady drawdown in the presence of a linear discontinuity. In: Rosenshein, J., Bennett G.D. (Eds.), Groundwater Hydraulics. AGU Water Res. Monogr., 9, 125-145.

Ferris, J.G., Knowles, D.B., Brown, R.H., Stallman R.W., 1962. Theory of aquifer tests. U.S.G.S. Water-Supply Paper. 1536-E, 69-174.

Ferroud A., Rafini S., Chesnaux R., 2019. Using flow dimension sequences to interpret nonuniform aquifers with constant-rate pumping-tests: A review. Journ. of Hydrology X, 1-25. https://doi.org/10.1016/j.hydroa.2018.100003

Gringarten, A.C., Henry, J., Ramey, H.J., Raghavan, R., 1974. Unsteady state pressure distributions created by a well with a single infinite conductivity vertical fracture. J. Soc. Petr. Eng. 14, 347-360.

Haneberg, W.C., 1995. Steady state groundwater flow across idealized faults. Water Resour Res, 31(7):1815-20.

Hantush, M.S., 1964. Hydraulics of wells. In: Chow, V.T. (Ed.), Advances in Hydroscience, vol. 1. Academic Press, New York, NY.

Hantush, M.S., 1966. Analysis of data from pumping tests in anisotropic aquifers. J. Geoph. Res. 72, 1709-1720. 
Kruseman, G.P., de Ridder, N.A., Verweij J.M., 1990. Analysis and evaluation of pumping test data. 2nd ed. Wageningen, The Netherlands. ILRI publication 47, 377p.

Lachassagne P., Wyns, R., Dewandel B., 2011. The fracture permeability of Hard Rock Aquifers is due neither to tectonics, nor to unloading, but to weathering processes. Terra Nova, 23, 145-161, 2011.

Lachassagne P., Dewandel B., Wyns R. 2021. Review: Hydrogeology of weathered crystalline/hard-rock aquifers_-guidelines for the operational survey and management of their groundwater resources. 1-34. Hydrog. Journ. https://doi.org/10.1007/s10040-021-02339-7

Perrin J., Ahmed S., Hunkeler D., 2011. The role of geological heterogeneities and piezometric fluctuations on groundwater flow and chemistry in hard-rock, southern India. Hydrogeology J. 19 (6), 1189-1201. http://dx.doi.org/10.1007/s10040-011-0745-y.

Maréchal J.C., Ladouche B., Dewandel B., Fleury P., Dörfliger N., 2014. Diagnostic Plots Applied to Well-Tests in Karst Systems. J. Mudry et al. (eds.), H2Karst Research in Limestone Hydrogeology, Envir. Earth Science, doi:10.1007/978-3-319-06139-9_9.

Maslia M.L., Prowell D.C., 1990. Effect of faults on fluid flow and chloride contamination in a carbonate aquifer system. J Hydrol;115: 1-49.

Maximov, V.A., 1962. Unsteady flow of compressible fluid to wells in a heterogeneous medium. Appl. Mech. Tech. Phys. 3, 109-112 (in Russian).

Neuman, S.P., Walter, G.R., Bentley, H.W., Ward, J.J., Gonzalez, D.D., 1984. Determination of horizontal aquifer anisotropy with three wells. Ground Water 22, 66-72.

Nind, T.E.W., 1965. Influence of absolute and partial hydrogeologic barriers on pump test results. Can. J. Earth Sci. 2, 309-323.

Rafini, S., Larocque, M., 2009. Insights from numerical modeling on the hydrodynamics of non-radial flow in faulted media. Adv. Water Resour. 32, 1170-1179. https://doi.org/10.1016/j.advwatres.2009.03.009.

Rafini, S., Larocque M.,, 2012. Numerical modeling of the hydraulic signatures of horizontal and inclined faults. Hydrogeol. J., 20, 337-350.

Raghavan, R., 2004. A review of applications to constrain pumping test responses to improve on geological description and uncertainty. Rev. of Geoph., 42, 1-29. 
790

791

792

793

794

795

796

797

798

799

800

801

802

803

804

805

806

807

808

809

810

811

812

813

Raghavan, R., 2010. A composite system with a planar interface. J. Petrol. Sci. Eng. 70, 229234.

Ramey, H.J., 1975. Interference analysis for anisotropic formations - a case history. J. Petr. Techn., 1290-1298.

Renard, Ph., Glenz, D., Mejias, M., 2009. Understanding diagnostic plots for well-test interpretation. Hydrogeol. J., 17, 589-600.

Spane, F.A., Wurstner, S.K., 1993. DERIV: a computer program for calculating pressures derivatives for use in hydraulic test analysis. Ground Water 31, 814-822.

Thiéry, D., 2010. Groundwater flow modelling in porous media using MARTHE. In: Tanguy, J.M. (Ed.), Modelling Software Volume 5. Environmental Hydraulics Series. Editions Wiley/ISTE, London, pp. 45-60.

Thiéry, D., 2015. Code de calcul MARTHE - Modélisation 3D des écoulements dans les hydro-systèmes - Notice d'utilisation de la version 7.5, BRGM/RP-64554-FR, Orléans.

Thiéry D., Amraoui N., Noyer M.-L., 2018. Modelling flow and heat transfer through unsaturated chalk - Validation with experimental data from the ground surface to the aquifer. J. of Hydrology, 556, 660-673. https://doi.org/10.1016/j.jhydrol.2017.11.041

Xiong Y., Xiong W., Cai M., Hou C. a, Wang C., 2017. Laboratory experiments of well testing for fracture-cave carbonate gas reservoirs. Petroleum, 3, 301-308. http://dx.doi.org/10.1016/i.petlm.2016.09.004

Xu Y., Hu W., Pang W., 2018. A new method for diagnosing caves in fault-karst carbonate reservoirs. Society of Petroleum Engineers, SPE-192971-MS. 1-8.

Yaxley, L.M., 1987. Effect of a partially communicating fault on transient pressure behavior. S.P.E. paper 14311, 60th Annual Fall Meeting, Las Vegas, Nv. 
814

815

816

817

818

819

820

821

822

823

824

825

826

827

828

829

830

831

832

833

834

835

836

837

838

839

840

\section{List of symbols:}

$a$ : distance to boundary $\mathrm{L} 1$ in $\mathrm{m}$

$\mathrm{e}^{x}$ : exponential function

$h$ : width of domain $\mathrm{D}^{*}$ (linear strip aquifer), in $\mathrm{m}$

$l$ : half-fracture length (in Domain 1), in m

$Q$ : pumping flow rate, in $\mathrm{m}^{3} \mathrm{~s}^{-1}$

$r_{w}:$ well radius, in $\mathrm{m}$

$S_{1}, S^{*}, S_{2}$ : storage coefficients of the right-side compartment (D1), the strip aquifer (D*), and the left-side compartment (D2), respectively, dimensionless

$s_{1}, s^{*}, s_{2}$ : drawdown of the right-side compartment (D1), the strip aquifer (D*), and the leftside compartment (D2), respectively, in $\mathrm{m}$

$s_{\text {frac }}$ : drawdown for a well intersecting and pumping a vertical fracture, in $\mathrm{m}$

$s_{D}$ : dimensionless drawdown for pumping in a well; $s_{D}\left(r_{w} / a, t_{D L}\right)=\frac{2 \pi T_{1}}{Q} s_{p w}\left(r_{w}, t\right)$

$s_{D f}$ : dimensionless drawdown for a well intersecting and pumping a vertical fracture;

$s_{D f}\left(a / l, t_{D f}\right)=\frac{2 \pi T_{1}}{Q} s_{p w f}\left(r_{w}, t\right)$

$\mathrm{t}_{D L}$ : dimensionless time according to the distance to the boundary (for pumping in a well);

$t_{D L}=T_{1} t /\left(S_{1} a^{2}\right)$

$\mathrm{t}_{D f}$ : dimensionless time according to the fracture half-length (for a well intersecting and pumping a vertical fracture); $t_{D f}=T_{1} t /\left(S_{1} l^{2}\right)$

$t$ : time, in seconds

$T_{1}, T^{*}, T_{2}$ : transmissivity of the right-side compartment (D1), the strip aquifer (D*), and the left-side compartment (D2) respectively, in $\mathrm{m}^{2} / \mathrm{s}$

$T_{x}^{*}$ and $T_{y}^{*}$ : principal axes of transmissivity anisotropy in the horizontal plane of the strip aquifer $\left(\mathrm{D}^{*}\right)$, in $\mathrm{m}^{2} / \mathrm{s}$

$x, y$ : coordinates of a Cartesian system, in $\mathrm{m}$

$\mathrm{W}(u)=\int_{u}^{\infty} \frac{\mathrm{e}^{-\varepsilon}}{\varepsilon} d \varepsilon$ with $\varepsilon$ a variable of integration. Well function.

$\alpha$ : angle of the fracture with the $x$-axis, radian 
842

843

844

$845 \frac{\partial^{2} s_{1}}{\partial x^{2}}+\frac{\partial^{2} s_{1}}{\partial y^{2}}+\frac{Q}{T_{1}} \delta(x) \delta(y)=\frac{s_{1}}{T_{1}} \frac{\partial s_{1}}{\partial t}$.

846

847

848

$849 \quad \frac{\partial^{2} s^{*}}{\partial x^{2}}+\frac{\partial^{2} s^{*}}{\partial y^{2}}=\frac{s^{*}}{T^{*}} \frac{\partial s^{*}}{\partial t}$

850

$851 \quad \frac{\partial^{2} s_{2}}{\partial x^{2}}+\frac{\partial^{2} s_{2}}{\partial y^{2}}=\frac{s_{2}}{T_{2}} \frac{\partial s_{2}}{\partial t}$

\section{Appendices}

\section{Appendix A Partial differential equation} source at $x=y=0$.

In D* (Butler and Liu, 1991):

And in D2 (Butler and Liu, 1991):

$\delta(x) \delta(y)$ is a combination of Dirac delta functions representing the pumping well as a line

852

853

Appendix B Calculation of strength coefficients for the first series of image-wells

854 according to boundaries L1 and L2 (Fig. 3a)

855

We first consider the first image according to L1 (boundary between D1 and D*; Fig. 3a). In

856 this case, the problem refers to the influence of a partial hydrologic barrier on a well test

857 (Bixel et al.,1963; Fenske, 1984; Maximov, 1962; Nind, 1965; Raghavan, 2010).

858

Applying the first boundary condition, it results that drawdown in Domain 1 is:

859

$s_{1}(x, y, t)=\frac{Q}{4 \pi T_{1}}\left[\mathrm{~W}\left(\frac{s_{1}}{4 T_{1} t}\left(x^{2}+y^{2}\right)\right)+\alpha_{0} \mathrm{~W}\left(\frac{s_{1}}{4 T_{1} t}\left([2 a-x]^{2}+y^{2}\right)\right)\right]$

860 and that drawdown in Domain $\mathrm{D}^{*}$ is:

861

$s^{*}(x, y, t)=\frac{Q}{4 \pi T^{*}} \beta_{0} \mathrm{~W}\left(\frac{s^{*}}{4 T^{*} t}\left(x^{2}+y^{2}\right)\right)$

862 Equating Eqs. (B.1) and (B.2), and for the condition $x=a$ (i.e. $s_{1}(a, y, t)=s^{*}(a, y, t)$ ) at the 863 boundary L1, we obtain:

$8641+\alpha_{0}=\frac{T_{1}}{T^{*}} \frac{\beta_{0}}{\gamma_{0}}$ with $\gamma_{0}=\frac{\mathrm{W}\left(\frac{s_{1}}{4 T_{1} t}\left(a^{2}+y^{2}\right)\right)}{\mathrm{W}\left(\frac{s^{*}}{4 T^{*} t}\left(a^{2}+y^{2}\right)\right)}$ 
865 Then, applying the second boundary condition at boundary L1, $T_{1} \frac{\partial s_{1}(a, y, t)}{\partial x}=T^{*} \frac{\partial s^{*}(a, y, t)}{\partial x}$, gives:

$8661-\alpha_{0}=\frac{\beta_{0}}{\tau_{0}}$ with $\tau_{0}=\frac{\mathrm{e}\left(-\frac{s_{1}}{4 T_{1} t}\left(a^{2}+y^{2}\right)\right)}{\mathrm{e}\left(-\frac{s^{*}}{4 T^{*} t}\left(a^{2}+y^{2}\right)\right)}$

867 Equating Eqs. (B.3) and (B.4) gives the strength coefficients $\alpha_{0}$ and $\beta_{0}$ :

868

$\alpha_{0}=\frac{T_{1} \tau_{0}-T^{*} \gamma_{0}}{T_{1} \tau_{0}+T^{*} \gamma_{0}} \quad$ and $\beta_{0}=\frac{2 T^{*} \tau_{0} \gamma_{0}}{T_{1} \tau_{0}+T^{*} \gamma_{0}}$

869 This case, which considers a system composed of only two domains (D1 and D*), is exactly

870 the solution proposed by Fenske (1984) for various diffusivity contrasts $\left(T_{1} / S_{1} \neq T^{*} / S^{*}\right)$.

871 Now, the pumping well must be imaged about the second boundary L2, and it results that 872 drawdown in Domain $D^{*}$ is:

$873 s^{*}(x, y, t)=\frac{Q}{4 \pi T^{*}}\left[\beta_{0} \mathrm{~W}\left(\frac{s^{*}}{4 T^{*} t}\left(x^{2}+y^{2}\right)\right)+\beta_{0}^{\prime} \mathrm{W}\left(\frac{s^{*}}{4 T^{*} t}\left[(2 a-x)^{2}+y^{2}\right]\right)\right]$

874 and that drawdown in Domain 2 is:

875

$s_{2}(x, y, t)=\frac{Q}{4 \pi T_{2}} \delta_{0} \mathrm{~W}\left(\frac{s_{2}}{4 T_{2} t}\left(x^{2}+y^{2}\right)\right)$

876 Equating Eqs. (B.6) and (B.7), and for the condition $x=a+h\left(s_{2}(a+h, y, t)=s^{*}(a+h, y, t)\right)$ at 877 the boundary L2, we obtain:

$878 \quad \beta_{0}+\beta_{0}^{\prime}=\frac{T^{*}}{T_{2}} \frac{\delta_{0}}{\gamma_{1}}$ with $\gamma_{1}=\frac{\mathrm{W}\left(\frac{S^{*}}{4 T^{*} t}\left[(a+h)^{2}+y^{2}\right]\right)}{\mathrm{W}\left(\frac{S_{2}}{4 T_{2} t}\left[(a+h)^{2}+y^{2}\right]\right)}$

879 Applying the second boundary condition at boundary L2, $T_{2} \frac{\partial s_{2}(a+h, y, t)}{\partial x}=T^{*} \frac{\partial s^{*}(a+h, y, t)}{\partial x}$, gives:

880

$\beta_{0}-\beta_{0}^{\prime}=\frac{\delta_{0}}{\tau_{1}}$ with $\tau_{1}=\frac{\mathrm{e}\left(-\frac{S^{*}}{4 T^{*} t}\left[(a+h)^{2}+y^{2}\right]\right)}{\mathrm{e}\left(-\frac{S_{2}}{4 T_{2} t}\left[(a+h)^{2}+y^{2}\right]\right)}$

881 Equating Eqs. (B.8) and (B.8) gives the strength coefficients $\beta_{0}^{\prime}$ and $\delta_{0}$ :

882

$\beta_{0}^{\prime}=-\beta_{0} \frac{T_{2} \tau_{1}-T^{*} \gamma_{1}}{T_{2} \tau_{1}+T^{*} \gamma_{1}}$ and $\delta_{0}=\frac{2 T_{2} \tau_{1} \gamma_{1}}{T_{2} \gamma_{1}+T^{*} \tau_{1}}$

884 Calculation of strength coefficients for the second series of image-wells according to L1 and 
Drawdown in Domain 1 is:

887

$s_{1}(x, y, t)=\frac{Q}{4 \pi T_{1}} \alpha_{1} \mathrm{~W}\left(\frac{s_{1}}{4 T_{1} t}\left([2 a+2 h-x]^{2}+y^{2}\right)\right)$

888

889

890

891

892

893

894

895

$\alpha_{1}=\beta_{0}^{\prime} \frac{2 T_{1}}{T_{1} \tau_{2}+T^{*} \gamma_{2}}, \beta_{1}=\beta_{0}^{\prime} \frac{T^{*} \gamma_{2}-T_{1} \tau_{2}}{T^{*} \gamma_{2}+T_{1} \tau_{2}}, \beta_{1}^{\prime}=-\beta_{1} \frac{T_{2} \tau_{3}-T^{*} \gamma_{3}}{T_{2} \tau_{3}+T^{*} \gamma_{3}}$ and $\delta_{1}=\beta_{1} \frac{2 T_{2} \tau_{3} \gamma_{3}}{T_{2} \gamma_{3}+T^{*} \tau_{3}}$

$896 \quad$ with $\quad \gamma_{2}=\frac{\mathrm{W}\left(\frac{s_{1}}{4 T_{1} t}\left([a+2 h]^{2}+y^{2}\right)\right)}{\mathrm{W}\left(\frac{s^{*}}{4 T^{*} t}\left([a+2 h]^{2}+y^{2}\right)\right)}, \quad \tau_{2}=\frac{\mathrm{e}\left(-\frac{s_{1}}{4 T_{1} t}\left([a+2 h]^{2}+y^{2}\right)\right)}{\mathrm{e}\left(-\frac{s^{*}}{4 T^{*} t}\left([a+2 h]^{2}+y^{2}\right)\right)}, \quad \gamma_{3}=\frac{\mathrm{W}\left(\frac{s^{*}}{4 T^{*} t}\left[(a+3 h)^{2}+y^{2}\right]\right)}{\mathrm{W}\left(\frac{S_{2}}{4 T_{2} t^{2}}\left[(a+3 h)^{2}+y^{2}\right]\right)}$ and

$897 \quad \tau_{3}=\frac{\mathrm{e}\left(-\frac{S^{*}}{4 T^{*} t}\left[(a+3 h)^{2}+y^{2}\right]\right)}{\mathrm{e}\left(-\frac{S_{2}}{4 T_{2} t}\left[(a+3 h)^{2}+y^{2}\right]\right)}$

898 and so on.

899

900

901

902

903

904

\section{Appendix C Drawdown solutions for the equal diffusivity case $\left(T_{1} / S_{1}=T^{*} / S^{*}=T_{2} / S_{2}=\eta\right)$}

For Domain 1:

$s_{1}(x, y, t)=$

$\frac{Q}{4 \pi T_{1}}\left\{\mathrm{~W}\left(\frac{x^{2}+y^{2}}{4 \eta t}\right)+\frac{T_{1}-T^{*}}{T_{1}+T^{*}} \mathrm{~W}\left(\frac{[2 a-x]^{2}+y^{2}}{4 \eta t}\right)+\right.$

$\left.\left(\frac{-2 T^{*}}{T_{1}+T^{*}}\right)\left(\frac{2 T_{1}}{T_{1}+T^{*}}\right)\left(\frac{T_{2}-T^{*}}{T_{2}+T^{*}}\right) \sum_{n=0,1,2}^{\infty}\left(\frac{T_{1}-T^{*}}{T_{1}+T^{*}}\right)^{n}\left(\frac{T_{2}-T^{*}}{T_{2}+T^{*}}\right)^{n} \mathrm{~W}\left(\frac{[2 a+2(n+1) h-x]^{2}+y^{2}}{4 \eta t}\right)\right\}$

905 
$906 S^{*}(x, y, t)=\frac{Q}{4 \pi T^{*}}\left\{\left(\frac{-2 T^{*}}{T_{1}+T^{*}}\right)\left(\frac{T_{2}-T^{*}}{T_{2}+T^{*}}\right) \sum_{n=0,1,2}^{\infty}\left(\frac{T_{1}-T^{*}}{T_{1}+T^{*}}\right)^{n}\left(\frac{T_{2}-T^{*}}{T_{2}+T^{*}}\right)^{n} \mathrm{~W}\left(\frac{[2 a+2(n+1) h-x]^{2}+y^{2}}{4 \eta t}\right)+\right.$
$\left.907 \quad\left(\frac{2 T^{*}}{T_{1}+T^{*}}\right) \sum_{n=0,1,2}^{\infty}\left(\frac{T_{1}-T^{*}}{T_{1}+T^{*}}\right)^{n}\left(\frac{T_{2}-T^{*}}{T_{2}+T^{*}}\right)^{n} \mathrm{~W}\left(\frac{[2 n h+x]^{2}+y^{2}}{4 \eta t}\right)\right\}$

908 And for Domain 2:

$909 s_{2}(x, y, t)=\frac{Q}{4 \pi T_{2}}\left(\frac{2 T^{*}}{T_{1}+T^{*}}\right)\left(\frac{2 T_{2}}{T_{2}+T^{*}}\right)\left\{\sum_{n=0,1,2}^{\infty}\left(\frac{T_{1}-T^{*}}{T_{1}+T^{*}}\right)^{n}\left(\frac{T_{2}-T^{*}}{T_{2}+T^{*}}\right)^{n} \mathrm{~W}\left(\frac{[n h+x]^{2}+y^{2}}{4 \eta t}\right)\right\}$

910 Note that for this particular case, strength coefficients are identical to the ones given by 911 Anderson (2006) for a steady-state solution.

912 
913

914

915

916

917

918

919

920

921

922

923

924

925

926

927

928

929

930

931

932

933

934

935

936

937

938

939

940

941

942

\section{Figure captions}

Figure 1. Conceptual sketches: a) of a pumping well and b) of a well intersecting and pumping a vertical fracture with finite length, located near a vertical infinite and anisotropic fault zone, (or another vertical geological discontinuity, strip aquifer). Domain D* (width $h$ ) separates two semi-infinite half-spaces of dissimilar properties (domains D1 and D2). The pumping well, or the pumped vertical fracture, is located in D1 and is not connected to D*.

Figure 2. Graphical display of the image-well series. (a) Image-well according to L1 and L2, graphical display of the image-well series. (b) Observation well located in domain D1. (c) Observation well located in domain $\mathrm{D}^{*}$. (d) Observation well located in domain D2. Modified from Anderson (2006). The pumping well is located in D1.

Figure 3. Graphical display of the first image-wells and calculation of the corresponding strength coefficients. (a) First series of image-wells according to L1 and L2. (b) Second series of images according to L1 and L2.

Figure 4. Type-curves of dimensionless drawdown $\left(\mathrm{s}_{\mathrm{D}}\right)$ and derivatives $\mathrm{s}_{\mathrm{D}}$, and dimensionless time $\left(\mathrm{t}_{\mathrm{DL}}\right)$ for a pumping well near a vertical infinite and isotropic fault zone $\left(\mathrm{D}^{*}\right) . T_{1} / S_{1}=0.1$, $T_{2} / S_{2}=0.5, T_{1} / T_{2}=20.0, h=5 \mathrm{~m}$. (a) Variations of transmissivity contrast $T^{*} / T_{1}\left(10^{-2}\right.$ to $\left.10^{3}\right)$ with $S^{*} / S_{1}=20.0$. (b) Variations of storativity contrast $S^{*} / S_{1}\left(10^{-3}\right.$ to $\left.10^{3}\right)$ with $T^{*} / T_{1}=100.0$.

Figure 5. Type-curves of dimensionless drawdown $\left(\mathrm{s}_{\mathrm{D}}\right)$ and derivatives $\mathrm{s}_{\mathrm{D}}$, and dimensionless time $\left(t_{D L}\right)$ for a pumping well near a vertical infinite and anisotropic fault zone. Anisotropy ratio varies $\left(10^{-3} \leq T^{*}{ }_{y} / T_{x}^{*} \leq 10^{3}\right) T_{1} / S_{1}=0.1, S^{*} / S_{1}=20.0, T^{*} / S^{*}=T_{2} / S_{2}=0.5, T_{1} / T_{2}=20.0, h=5 \mathrm{~m}$.

Figure 6. Comparison of drawdown, s, and derivative, s', computed with MARTHE software (plain dots: s; open dots: s') and the analytical solutions (plain curves: s; dotted curves: s') for the anisotropic case (Eqs. 4-6 with Eqs. 7-9). See figure and text for model parameters. The inserted tables show RMSE values for various observation-well locations ( $x, y$ coordinates). (a) Model 1: $T^{*}: 10^{-1} \mathrm{~m}^{2} / \mathrm{s}$ and $S^{*}: 10^{-1}$. (b) Model $2 T^{*}: 3 \times 10^{-3} \mathrm{~m}^{2} / \mathrm{s}$ and $S^{*}: 2 \times 10^{-2}$. In both cases, $T^{*}{ }_{y} / T^{*}=10.0$. '

Figure 7. Conceptual sketch of flow behaviour through boundaries L1 and L2, where the transmissivity of the central compartment ( $\mathrm{D}^{*}$, fault zone) is higher than that of other compartments. Black arrows: normal flow from compartment $\mathrm{D}^{*}$ to D1, or D2 to $\mathrm{D}^{*}$. Blue arrows: flow reversal from D1 to D*. Pumping is performed in D1. 
943

944

945

946

947

Figure 8. Flow profiles through both discontinuities. (a) L1 and (b) L2 with various aquifer properties after 21 days of pumping $\left(t=3 \times 10^{4} \mathrm{~min}\right.$ and $\left.Q=1 \mathrm{~m} 3 / \mathrm{h}\right)$. The pumping well is located at $10.0 \mathrm{~m}$ from a 5 -m-wide fault zone $(a=10.0 \mathrm{~m}$ and $h=5.0 \mathrm{~m})$. See figure and text for model parameters.

Figure 9. Flow profiles through both discontinuities. (a) L1 and (b) L2 at various times of pumping, $t=1,7,30,200,500,3 \times 10^{3}, 3 \times 10^{4}$ and $10^{8}$ min. It corresponds to case $\mathrm{H}$ on Figure 7 (the anisotropic case $T^{*}{ }_{y} / T^{*}=50.0$ ). See figure and text for model parameters.

Figure 10. (a) Time-variations of the various flow components through both discontinuities L1 and L2. (b) Net flow from strip aquifer D*. (c) Corresponding drawdowns and their derivatives at the pumping well. Two examples are shown, the one given on Figure 8 $\left(T^{*}{ }_{y} / T_{x}^{*}=50.0\right.$, case $\left.\mathrm{H}\right)$ and the one where $\mathrm{D}^{*}$ is isotropic $\left(T^{*} / T_{x} *=1.0\right)$, all other parameters remaining unchanged.

Figure 11. Type-curves of dimensionless drawdown $\left(\mathrm{s}_{\mathrm{Df}}\right)$ and derivatives $\mathrm{s}_{\mathrm{Df}}$ ', and dimensionless time $\left(t_{D f}\right)$ for a well intersecting and pumping a vertical fracture near a vertical infinite and anisotropic strip aquifer (Fig. 1b). Variations of $a / l$ ratios (from 1 to 10), $T_{1} / S_{1}=0.1, T^{*} / S^{*}=T_{2} / S_{2}=0.5, T^{*}{ } / T^{*}{ }_{x}=10.0, T^{*} / T_{1}=100.0 ; T_{1} / T_{2}=20.0, h=5 \mathrm{~m}$.

Figure 12. Flow profiles through both boundaries: (a) L1 and (b) L2 for a well intersecting and pumping a vertical fracture near a vertical infinite fault zone at $t=3 \times 10^{4} \mathrm{~min} . T_{l}=10^{-}$ ${ }^{3} \mathrm{~m}^{2} / \mathrm{s}, S_{1}=5 \times 10^{-3}, T^{*}=2 \times 10^{-2} \mathrm{~m}^{2} / \mathrm{s}, S^{*}=10^{-2}, T^{*} y / T^{*} x=50.0, T_{2}=10^{-4} \mathrm{~m}^{2} / \mathrm{s}, S_{2}=10^{-3}, h=5 \mathrm{~m}$ and $a=10 \mathrm{~m}, Q=1 \mathrm{~m}^{3} / \mathrm{h}$, fracture length $2 l=20 \mathrm{~m}$, and $\alpha=0^{\circ}, 45^{\circ}$ and $90^{\circ}$ ( $a$ : angle of the fracture according to the $x$-axis). We also presented the case where a well is pumped without fracture (grey curve H on Fig. 8).

Figure 13. (a) Time-variations of flux along L1 and L2. (b) Net flow from fault zone D*. (c) Corresponding drawdown and derivatives at a well intersecting and pumping a fracture. Aquifer properties are identical to the examples shown on Fig. 12. We also present the case where a well is pumped, without fracture (in grey, the same as on Fig. 9). 


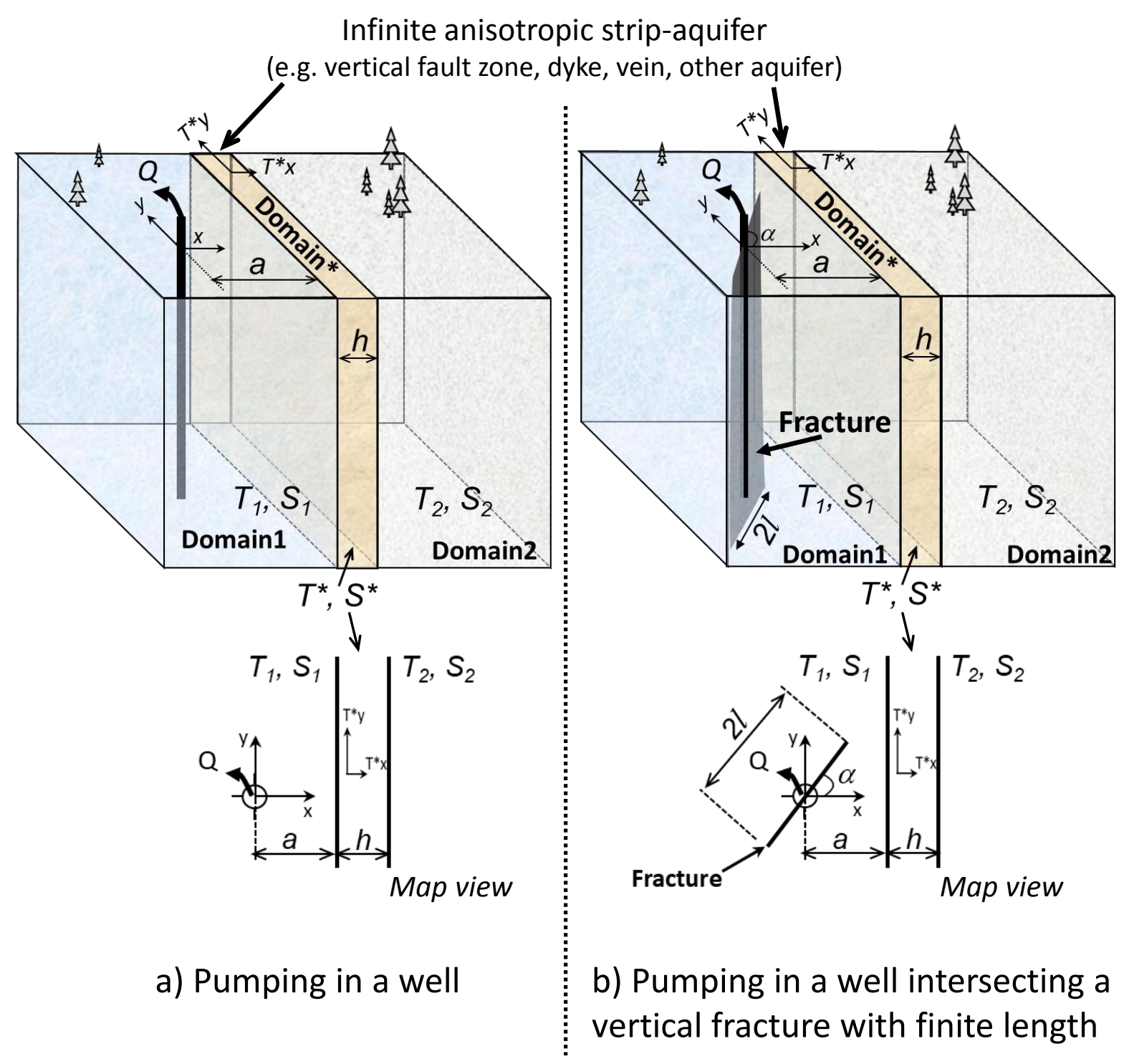

Figure 1 


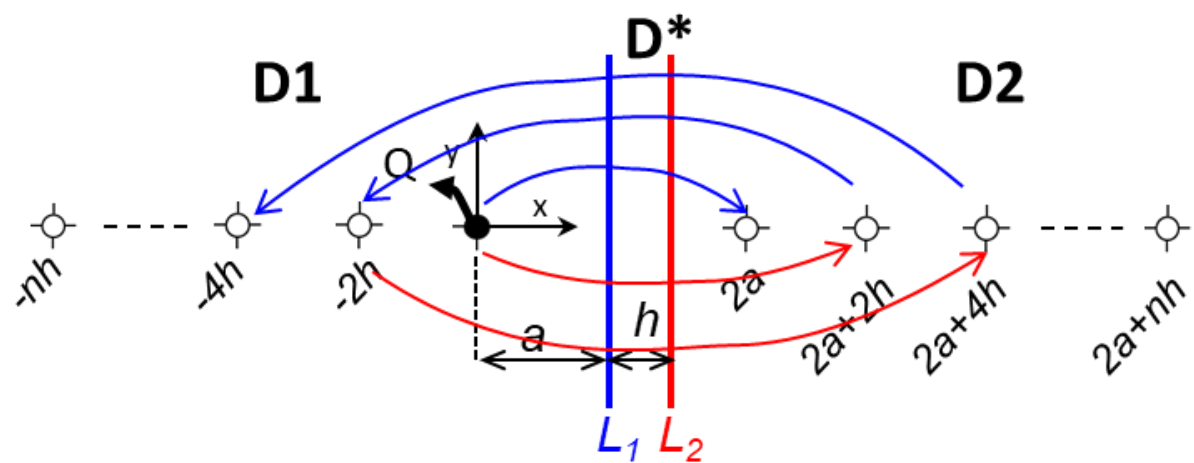

(a) Image-wells according to boundaries L1 and L2

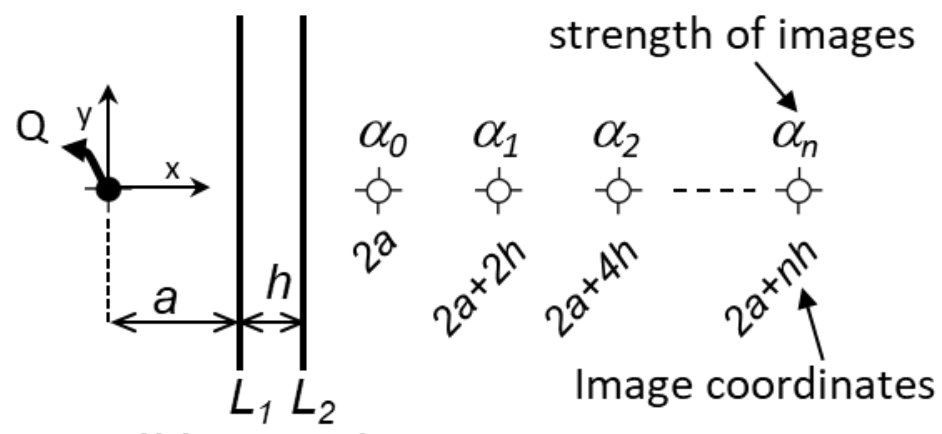

(b) For an observation well located in Domain 1

strength of images

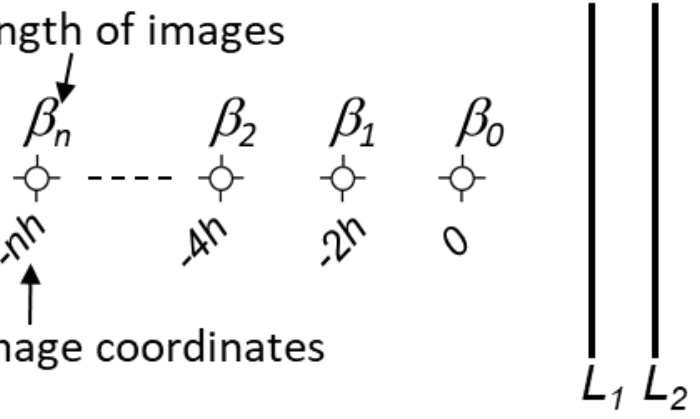

strength of images

$\begin{array}{llll}\beta_{0}^{\prime} & \beta_{1}^{\prime} & \beta_{2}^{\prime} & \beta_{n}^{\prime}\end{array}$<smiles>C#CC=C=C=C</smiles>

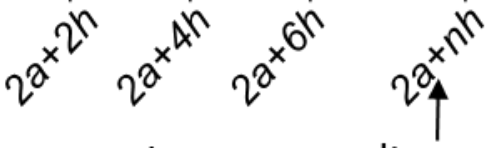

Image coordinates

(c) for an observation well located in Domain *

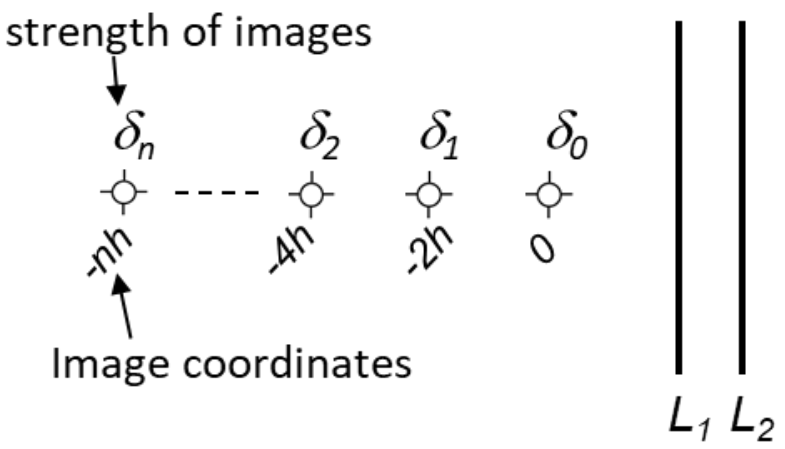

(d) for an observation well located in Domain 2

Figure 2 


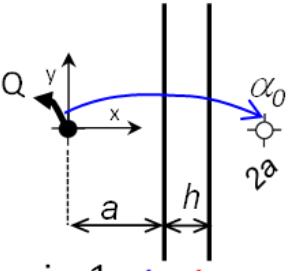

Domain $1 L_{1} L_{2}$
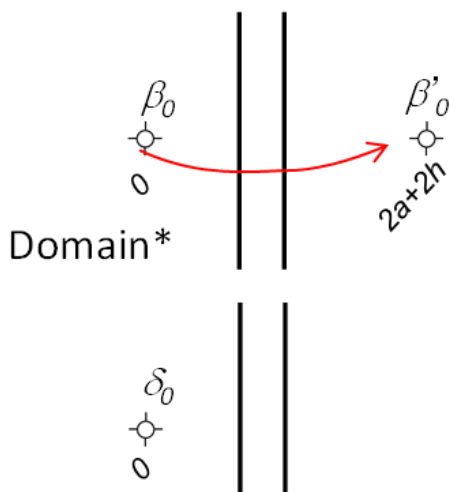

Domain 2 strength of image

for $s_{1}(x, y, t)$

$\alpha_{0}=\frac{T_{1} \tau_{0}-T^{*} \gamma_{0}}{T_{1} \tau_{0}+T^{*} \gamma_{0}}$

strength of images

for $s^{*}(x, y, t)$

$\beta_{0}=\frac{2 T^{*} \tau_{0} \gamma_{0}}{T_{1} \tau_{0}+T^{*} \gamma_{0}}$

$\beta_{0}^{\prime}=-\beta_{0} \frac{T_{2} \tau_{1}-T^{*} \gamma_{1}}{T_{2} \tau_{1}+T^{*} \gamma_{1}}$

strength of image

for $s_{2}(x, y, t)$

$\delta_{0}=\frac{2 T_{2} \tau_{1} \gamma_{1}}{T_{2} \gamma_{1}+T^{*} \tau_{1}}$
With

$\gamma_{0}=\frac{\mathrm{w}\left(\frac{S_{1}}{4 T_{1} t}\left(a^{2}+y^{2}\right)\right)}{\mathrm{W}\left(\frac{s^{*}}{4 T^{*} t}\left(a^{2}+y^{2}\right)\right)}$

$\tau_{0}=\frac{\mathrm{e}\left(-\frac{S_{1}}{4 T_{1} t}\left(a^{2}+y^{2}\right)\right)}{\mathrm{e}\left(-\frac{s^{*}}{4 T^{*} t}\left(a^{2}+y^{2}\right)\right)}$

$\gamma_{1}=\frac{\mathrm{W}\left(\frac{S^{*}}{4 T^{*} t}\left[(a+h)^{2}+y^{2}\right]\right)}{\mathrm{W}\left(\frac{S_{2}}{4 T_{2} t}\left[(a+h)^{2}+y^{2}\right]\right)}$

$\tau_{1}=\frac{\mathrm{e}\left(-\frac{S^{*}}{4 T^{*} t}\left[(a+h)^{2}+y^{2}\right]\right)}{\mathrm{e}\left(-\frac{S_{2}}{4 T_{2} t}\left[(a+h)^{2}+y^{2}\right]\right)}$

(a) first series of image-well according to $L 1$ and $L 2$
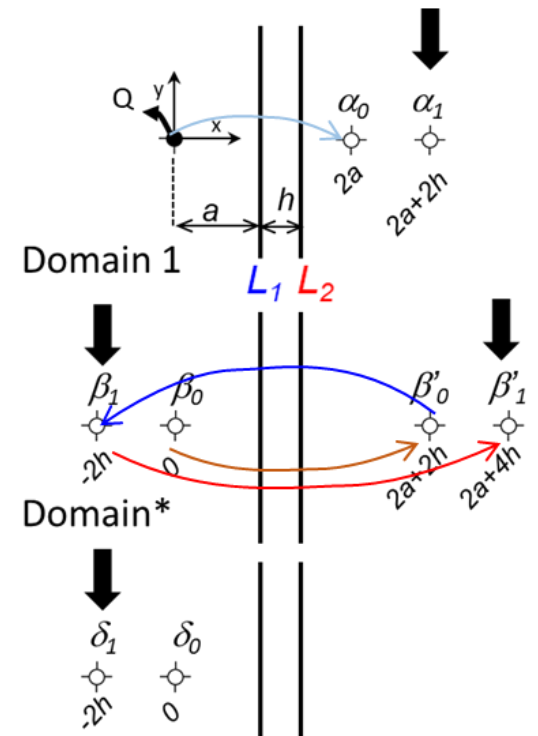

Domain 2 strength of image

for $s_{1}(x, y, t)$

$\alpha_{1}=\beta_{0}^{\prime} \frac{2 T_{1}}{T_{1} \tau_{2}+T^{*} \gamma_{2}}$

strength of images

for $s^{*}(x, y, t)$

$\beta_{1}=\beta_{0}^{\prime} \frac{T^{*} \gamma_{2}-T_{1} \tau_{2}}{T^{*} \gamma_{2}+T_{1} \tau_{2}}$

$\beta_{1}^{\prime}=-\beta_{1} \frac{T_{2} \tau_{3}-T^{*} \gamma_{3}}{T_{2} \tau_{3}+T^{*} \gamma_{3}}$

strength of image

for $s_{2}(x, y, t)$

$\delta_{1}=\beta_{1} \frac{2 T_{2} \tau_{3} \gamma_{3}}{T_{2} \gamma_{3}+T^{*} \tau_{3}}$
With

$$
\gamma_{2}=\frac{\mathrm{W}\left(\frac{S_{1}}{4 T_{1} t}\left([a+2 h]^{2}+y^{2}\right)\right)}{\mathrm{W}\left(\frac{s^{*}}{4 T^{*} t}\left([a+2 h]^{2}+y^{2}\right)\right)}
$$$$
\tau_{2}=\frac{\mathrm{e}\left(-\frac{S_{1}}{4 T_{1} t}\left([a+2 h]^{2}+y^{2}\right)\right)}{\mathrm{e}\left(-\frac{s^{*}}{4 T^{*} t}\left([a+2 h]^{2}+y^{2}\right)\right)}
$$$$
\gamma_{3}=\frac{\mathrm{W}\left(\frac{S^{*}}{4 T^{*} t}\left[(a+3 h)^{2}+y^{2}\right]\right)}{\mathrm{W}\left(\frac{S_{2}}{4 T_{2} t}\left[(a+3 h)^{2}+y^{2}\right]\right)}
$$

$\tau_{3}=\frac{\mathrm{e}\left(-\frac{S^{*}}{4 T^{*} t}\left[(a+3 h)^{2}+y^{2}\right]\right)}{\mathrm{e}\left(-\frac{S_{2}}{4 T_{2} t}\left[(a+3 h)^{2}+y^{2}\right]\right)}$

(b) second series of images according to L1 and L2

Figure 3 
Advances in Water Resources - https://doi.org/10.1016/j.advwatres.2021.104107

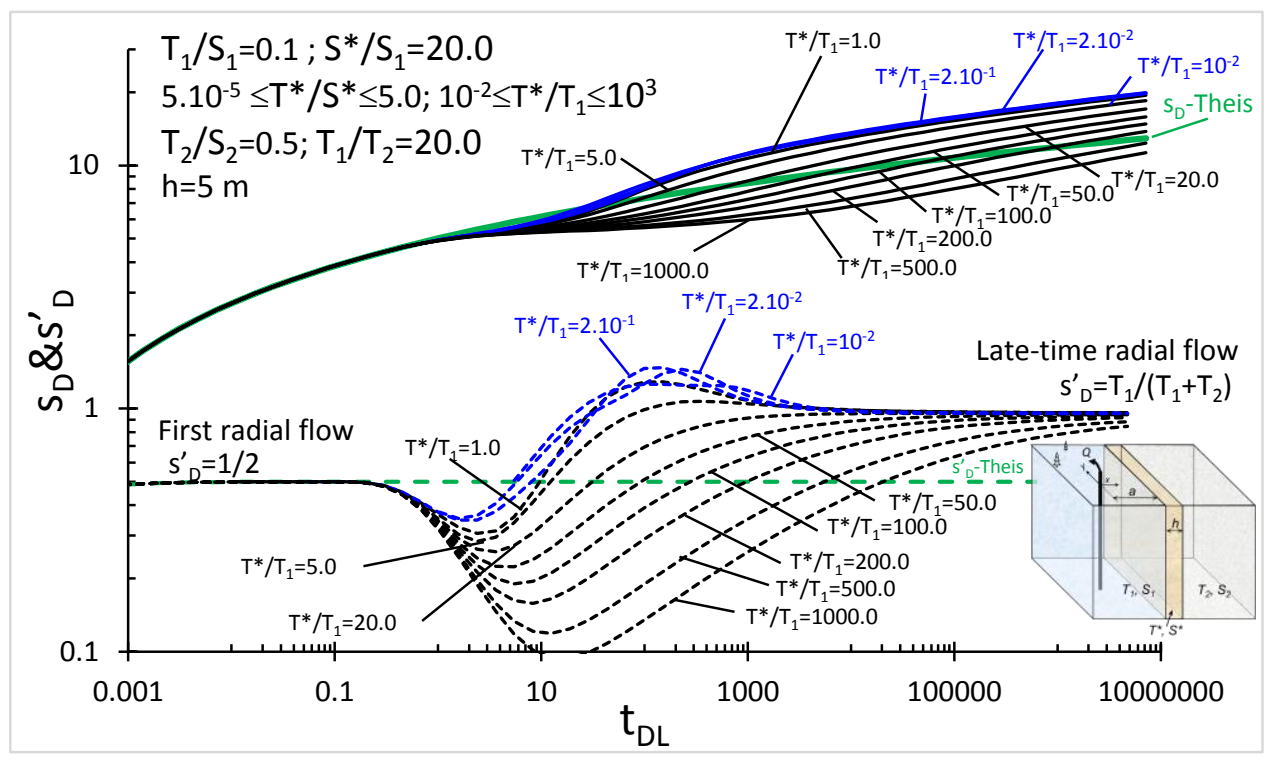

(a)

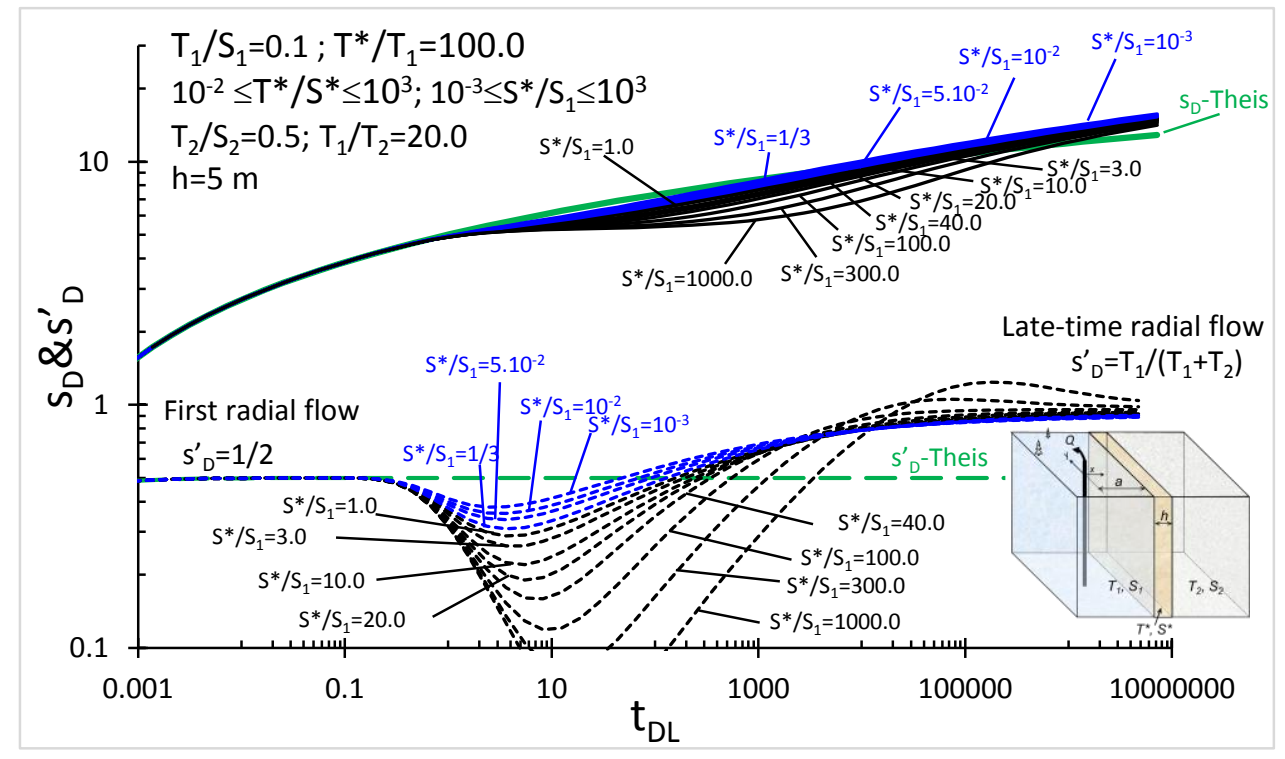

(b)

Figure 4 
Advances in Water Resources - https://doi.org/10.1016/j.advwatres.2021.104107

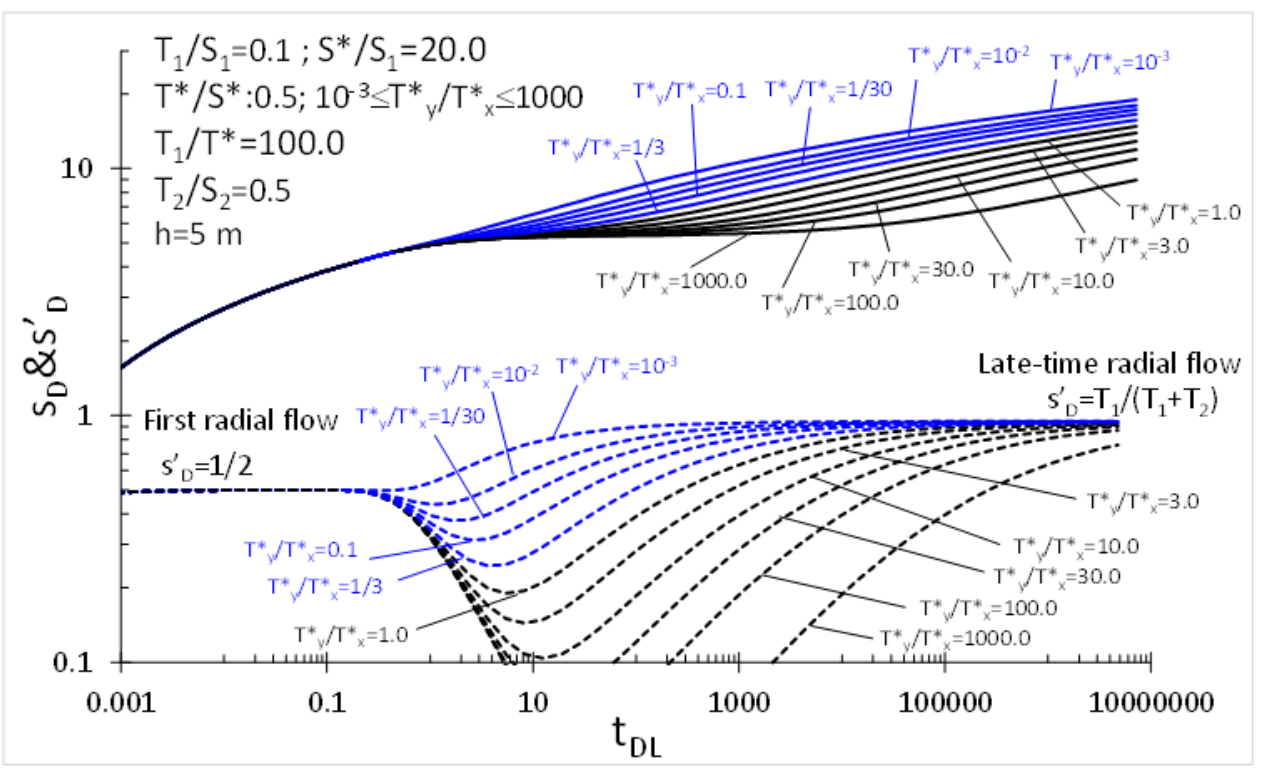

Figure 5

975

976 

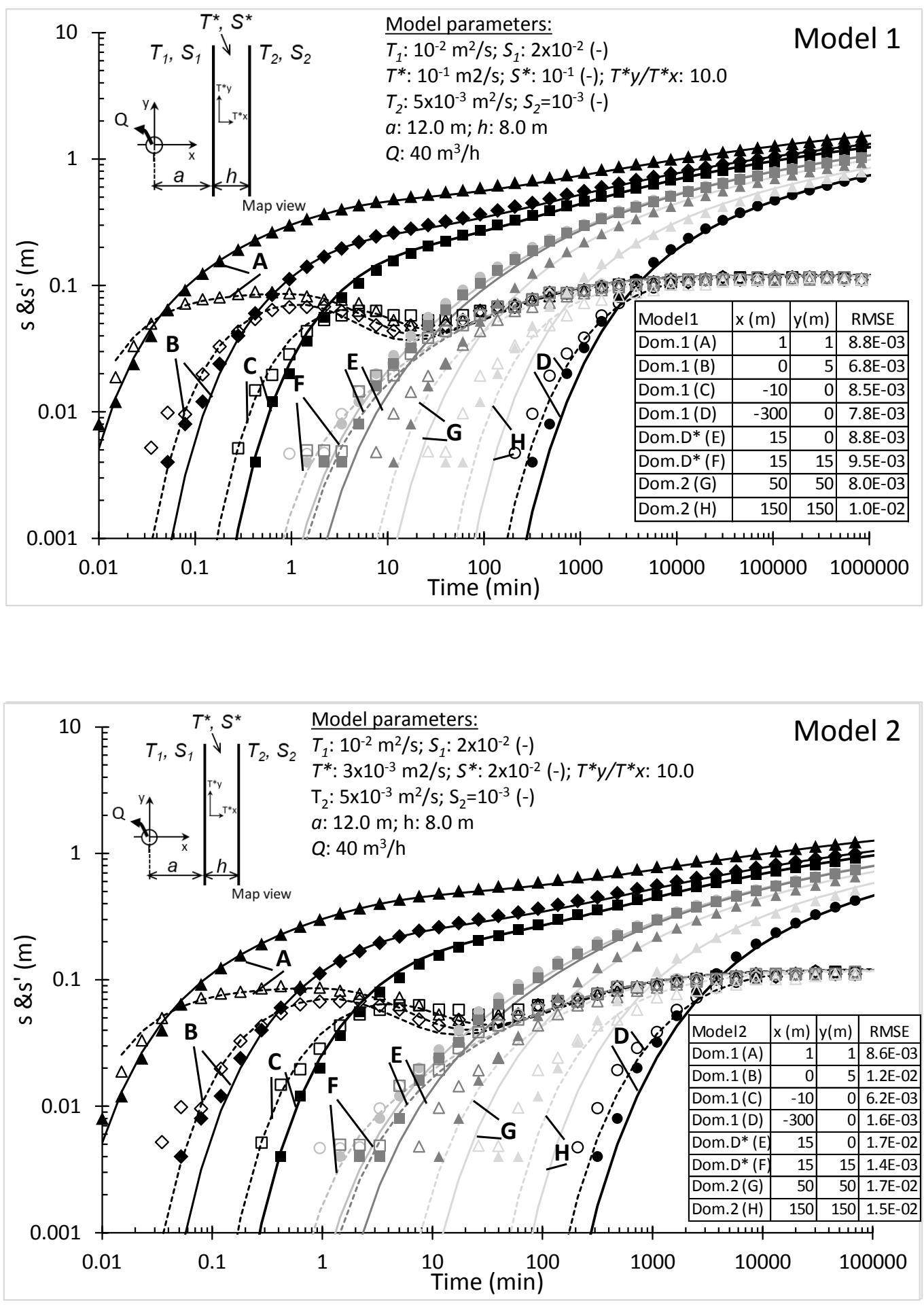

Figure 6 


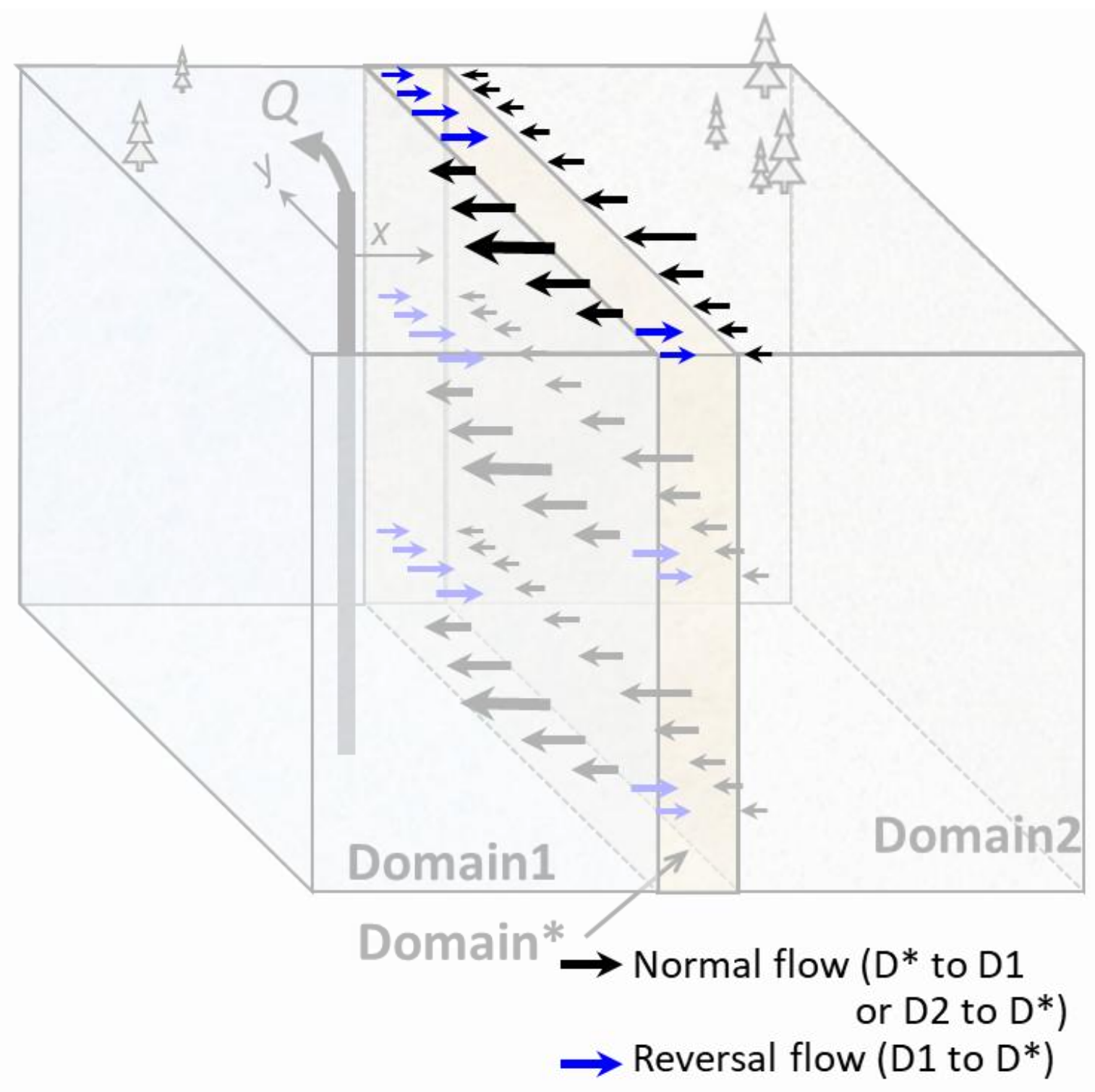

Figure 7 


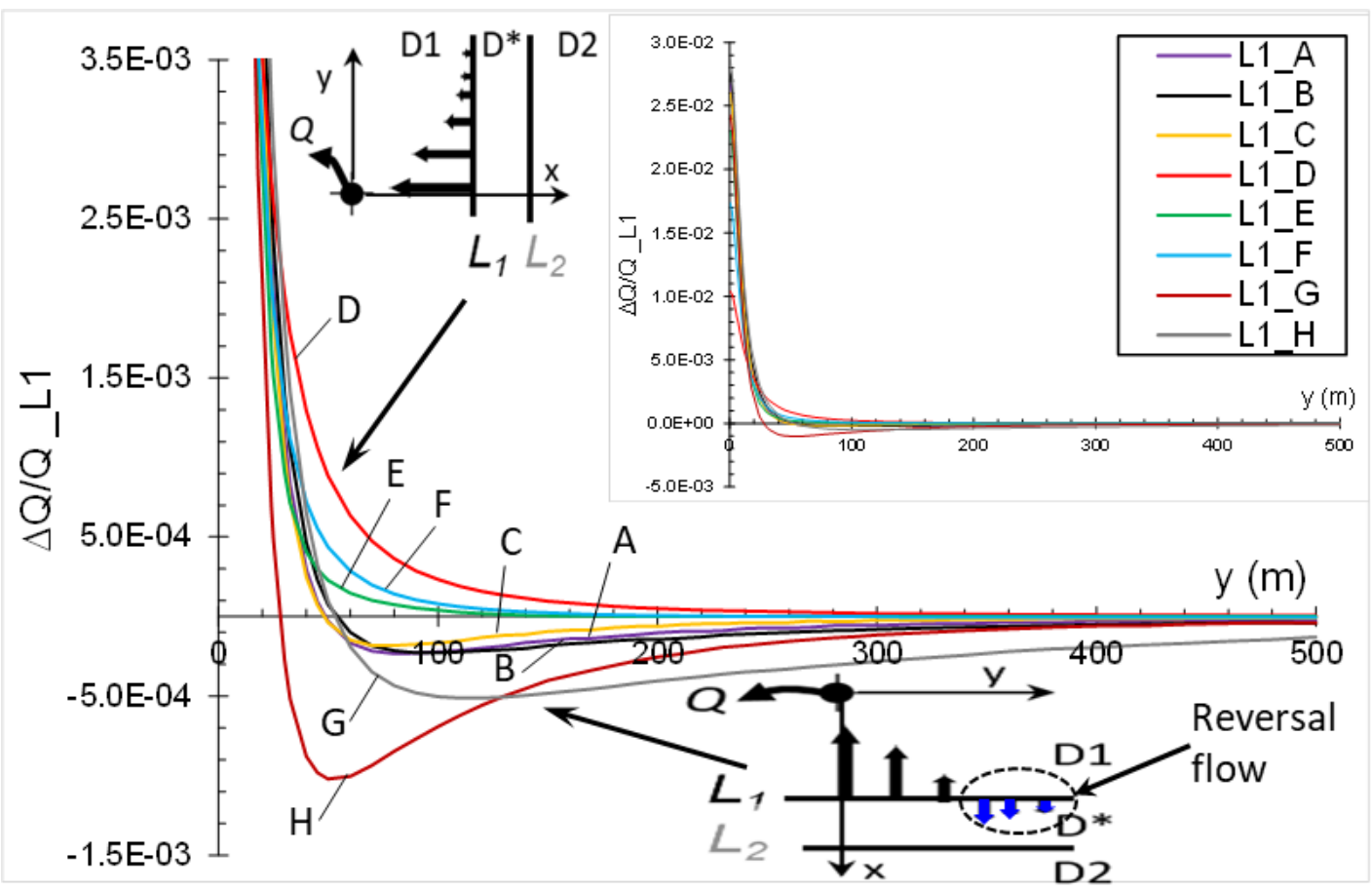

(a)

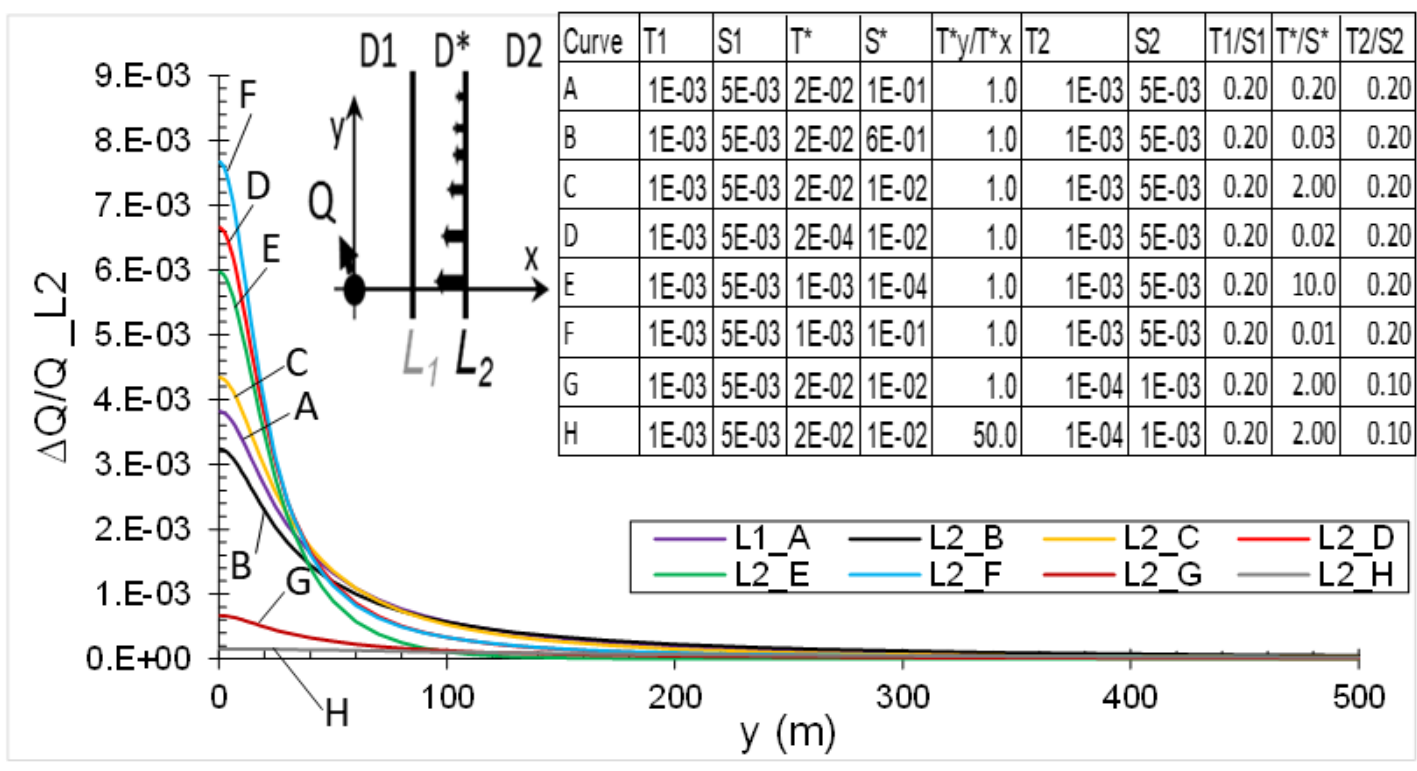

(b)

Figure 8 


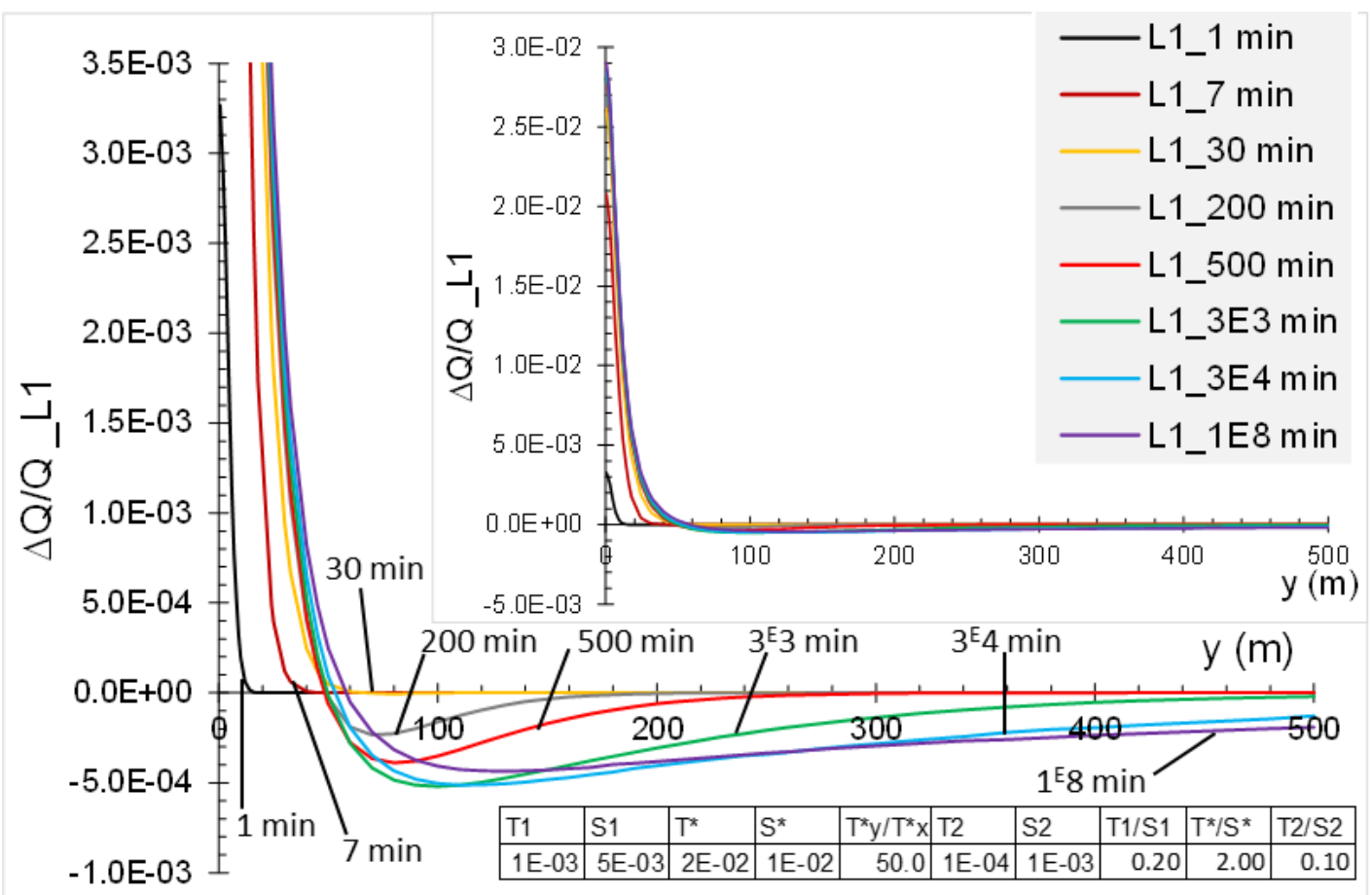

(a)

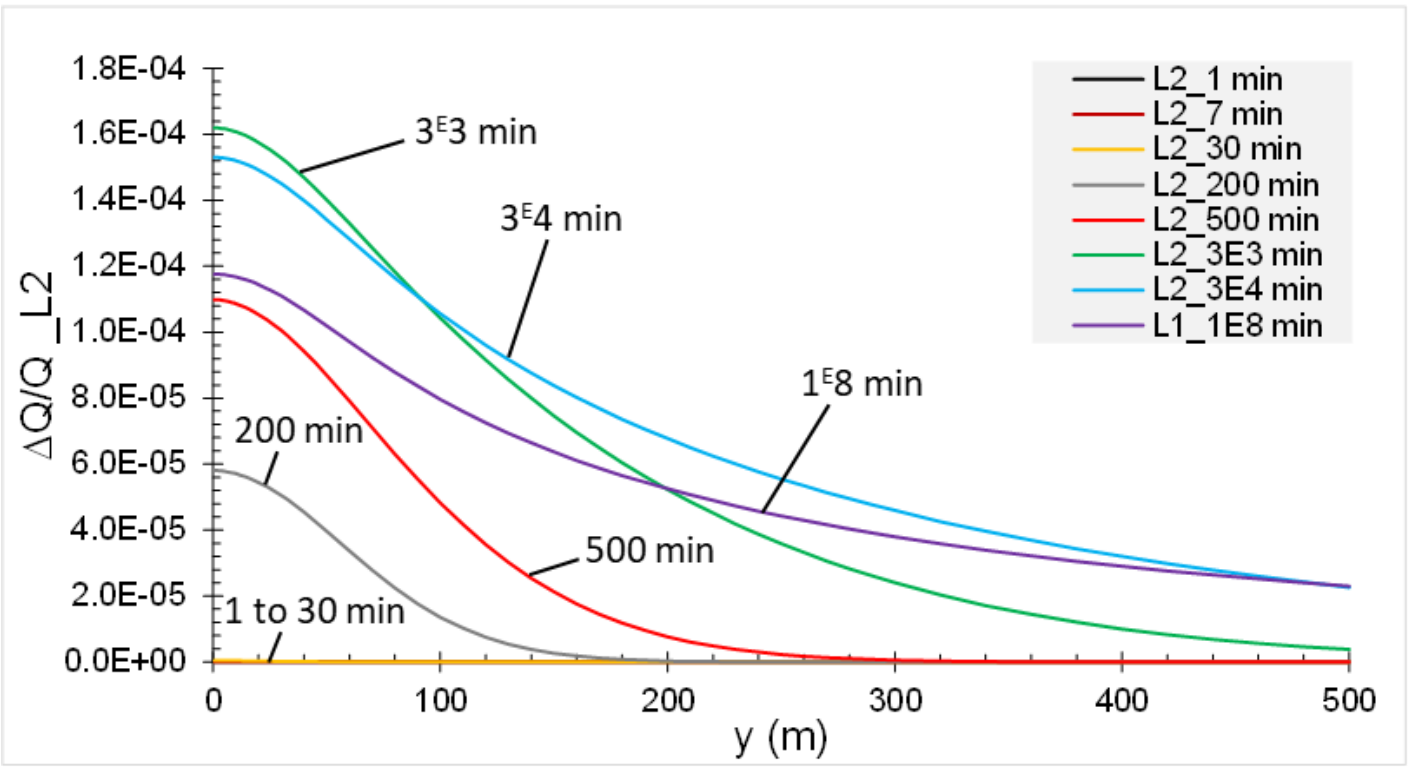

(b)

Figure 9 


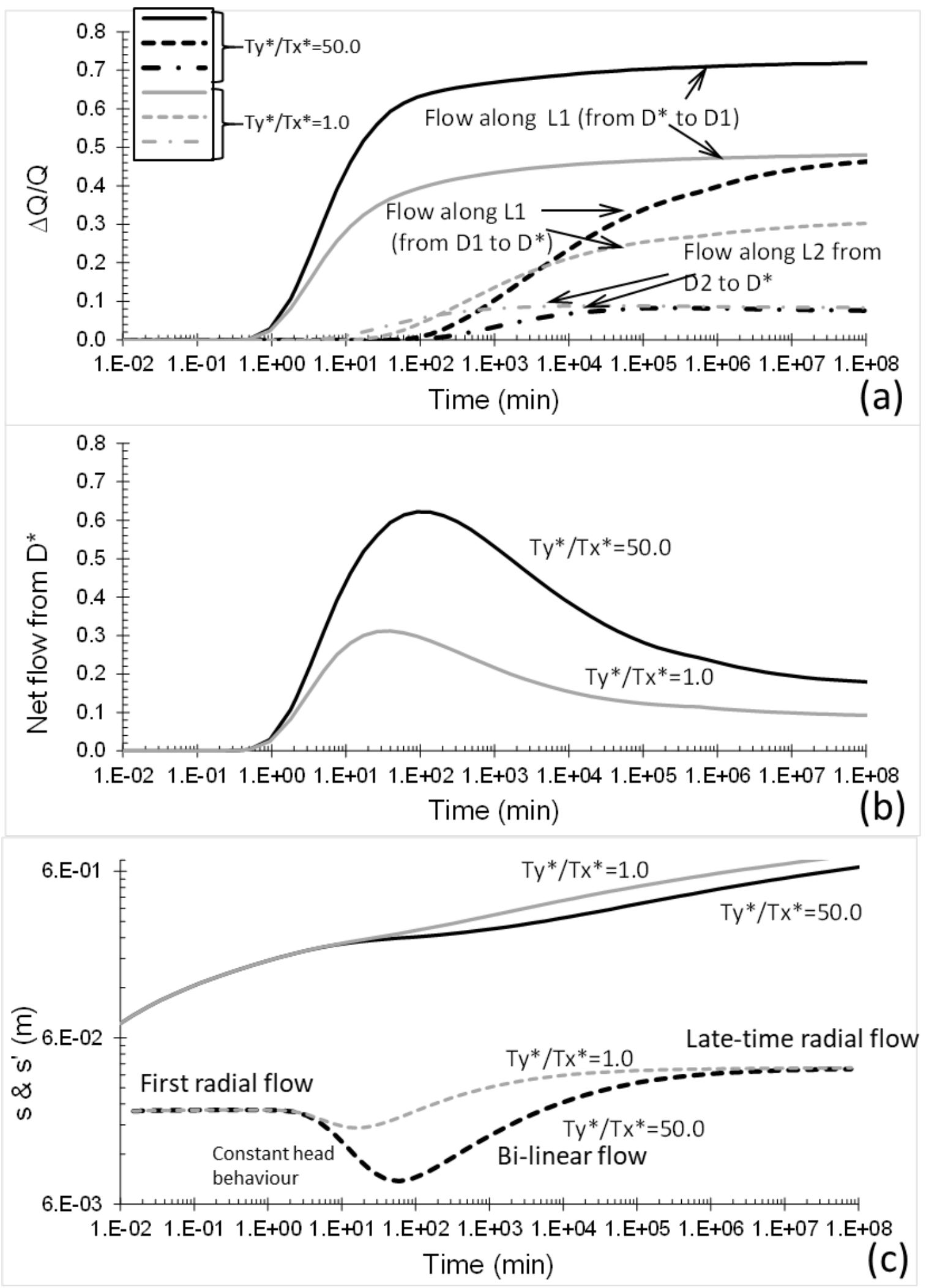

Figure 10 


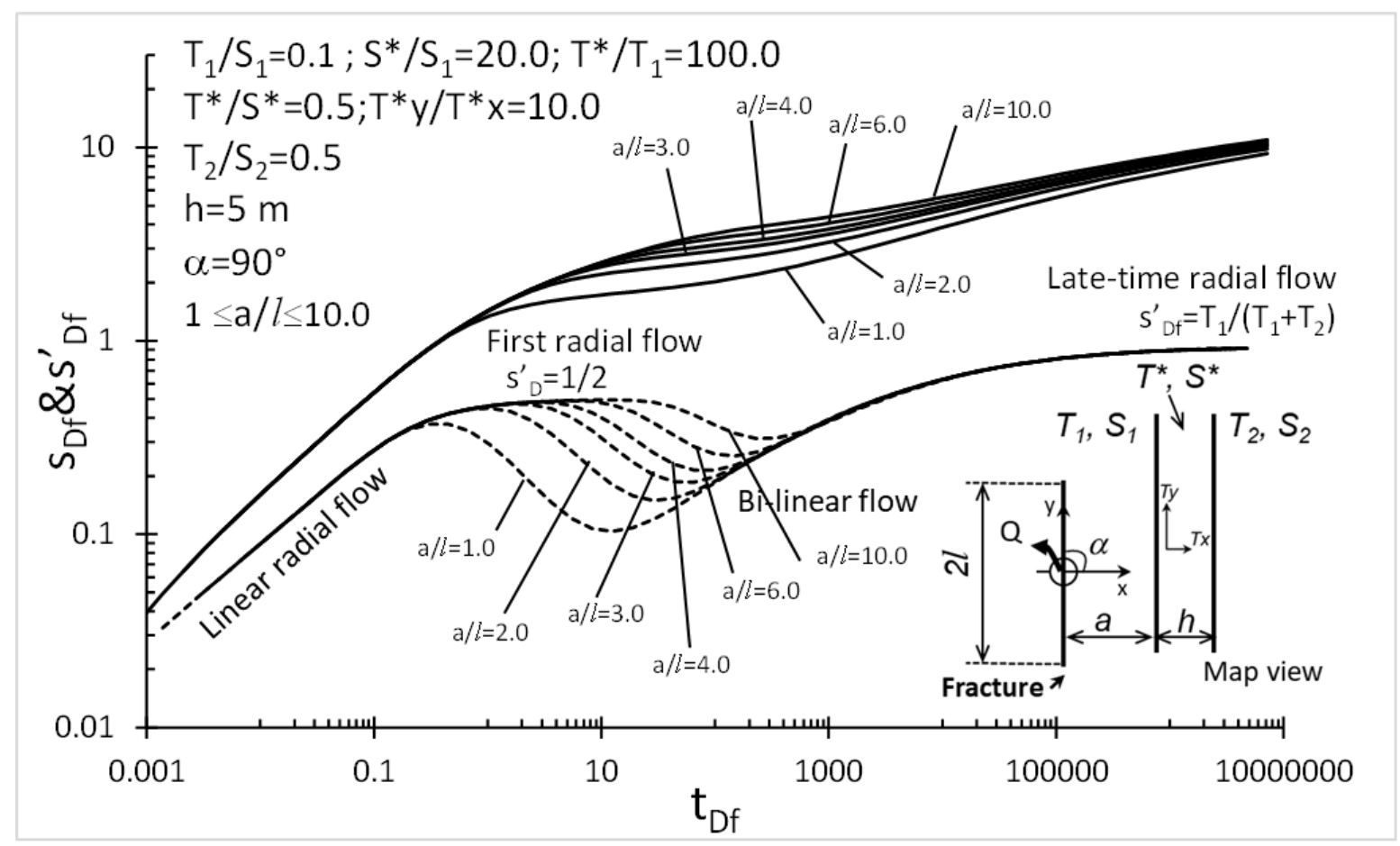

Figure 11 


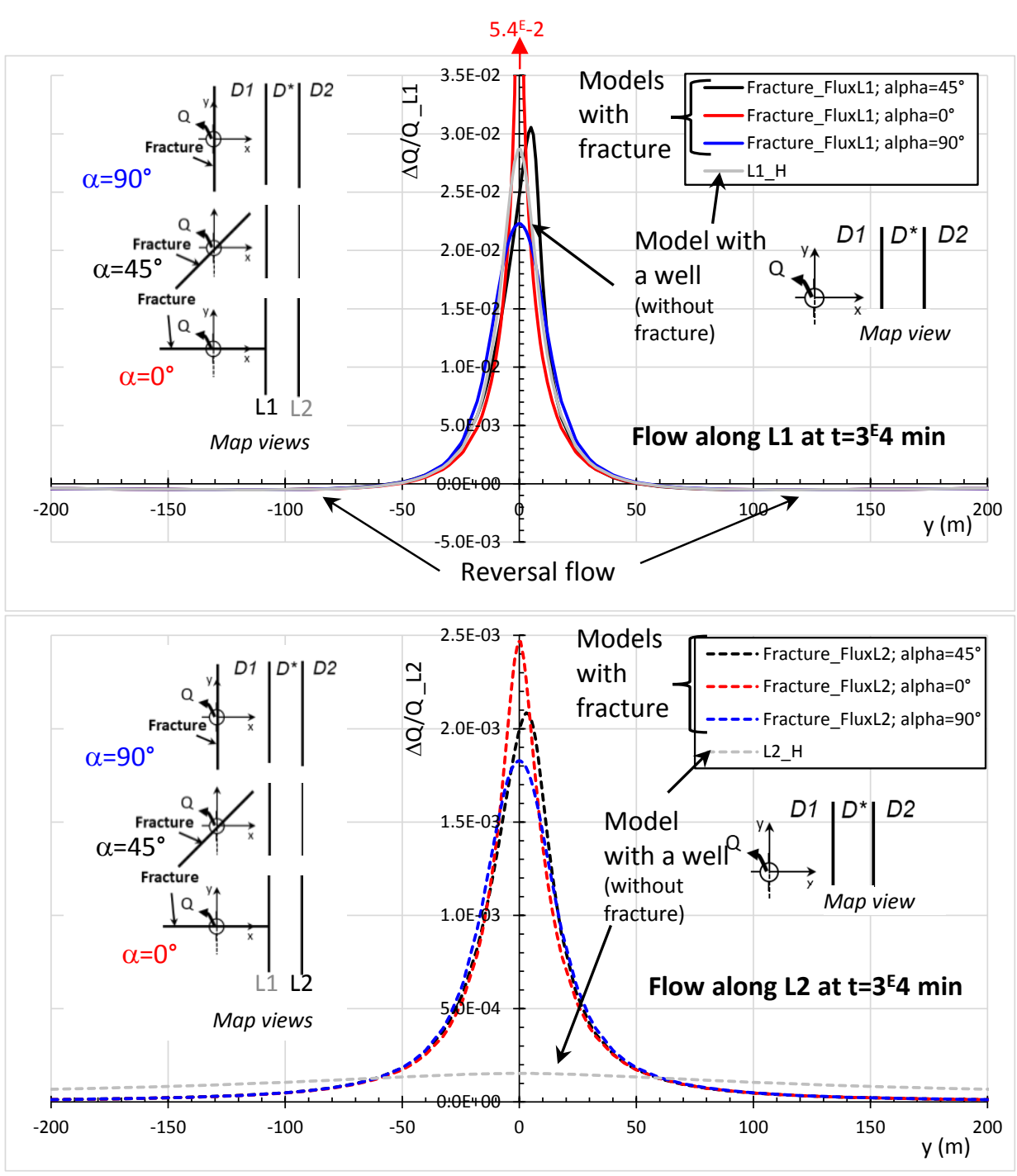

(a)

(b)

Figure 12 


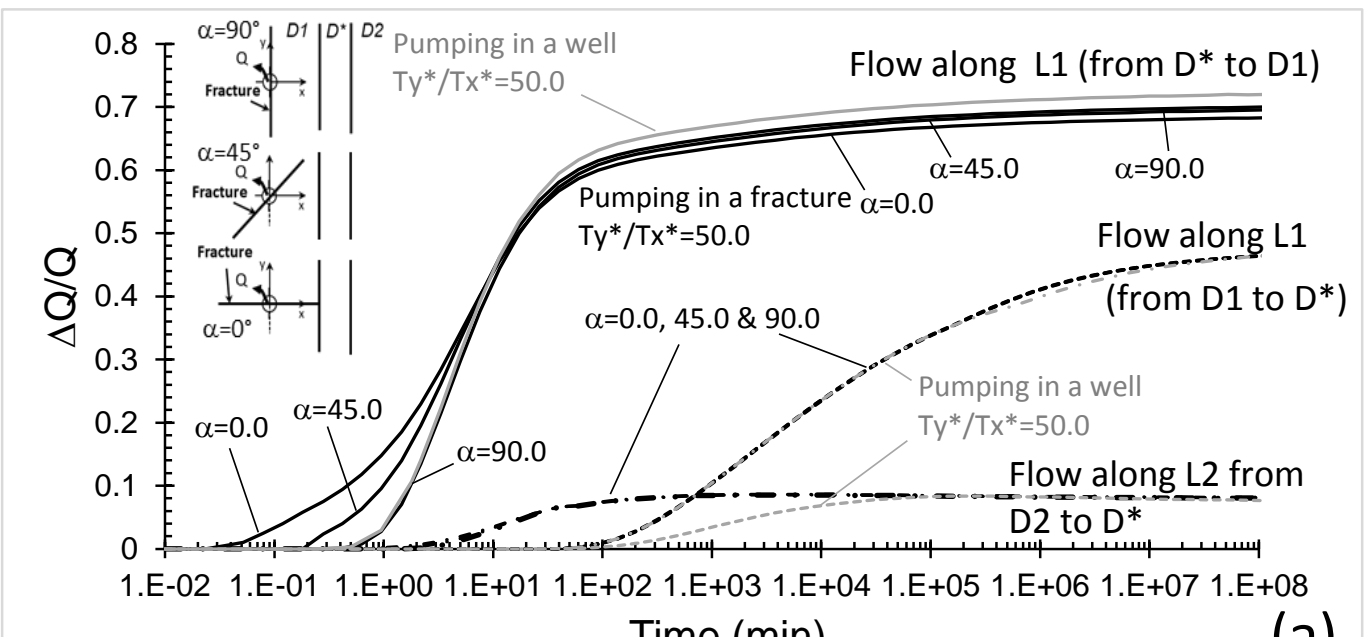

Time (min)

(a)
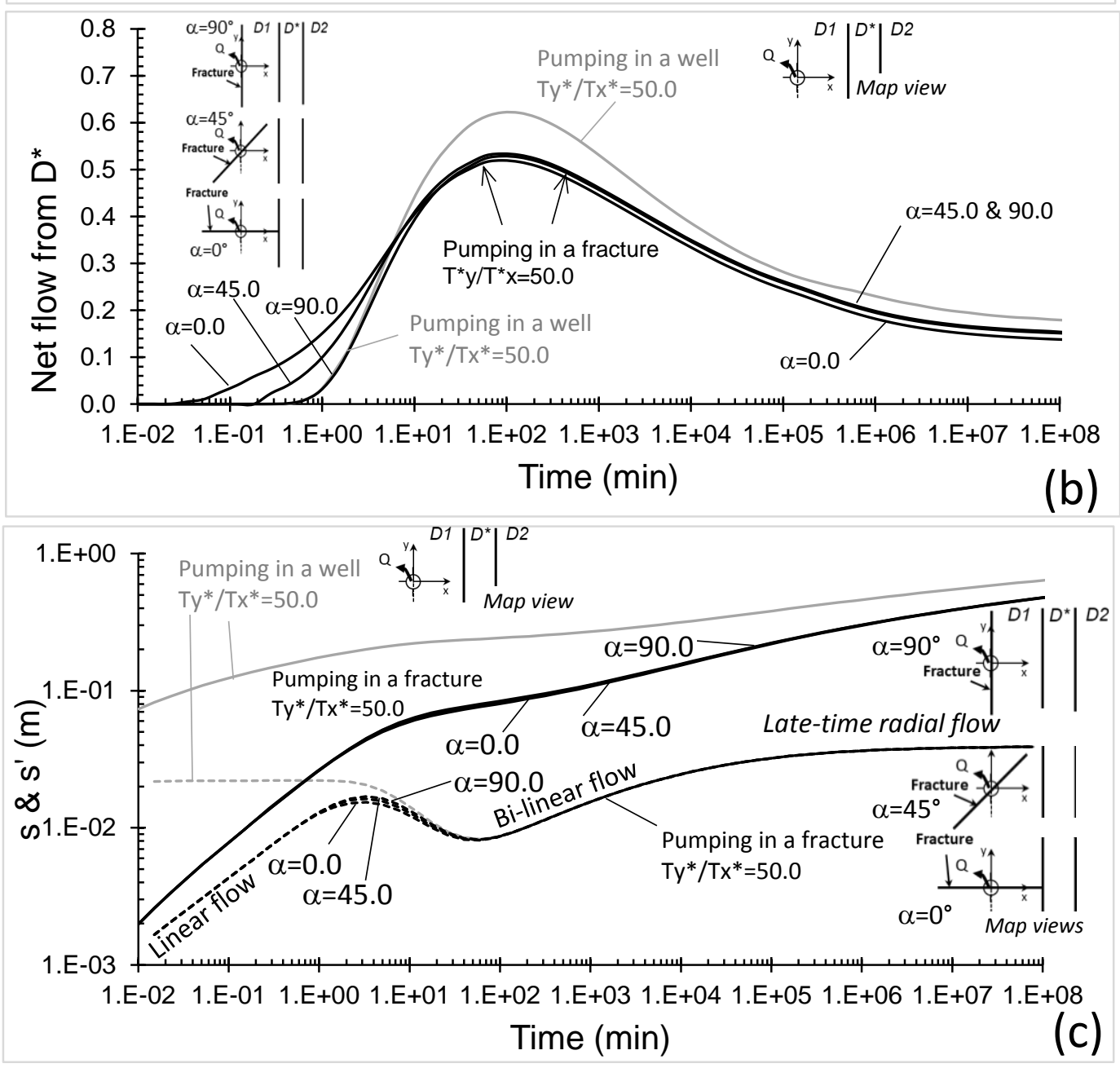

Figure 13 